\title{
Inanimate figure tracing and ex vivo pig stomach models to teach endoscope control and ESD: Description of models and preliminary results.
}

HMC Shantha Kumara ( $\nabla$ cmudiyansela@northwell.edu )

Lenox Hill Hospital https://orcid.org/0000-0001-9106-797X

Abhinit Shah

Lenox Hill Hospital

Erica Pettke

Swedish Medical Center

\section{Elie Sutton}

Mount Sinai West Medical Center

Geoffrey Bellini

Aurora St Luke's Medical Center

Jaspreet Sandhu

Brookdale University Hospital Medical Center Marie Smith Schwartz Medical Library

Carl Winkler

Mount Sinai West Medical Center

Xiaohong Yan

Lenox Hill Hospital

Vesna Cekic

Lenox Hill Hospital

Shantha Kumara HMC

Lenox Hill Hospital

Nipa Dilip Gandhi

Mount Sinai West Medical Center

Richard L Whelan

Lenox Hill Hospital

Research article

Keywords: ESD, endoscopic training, ex vivo pig stomach model, inanimate training models

Posted Date: January 3rd, 2020

DOI: https://doi.org/10.21203/rs.2.20042/v1 
License: (c) (i) This work is licensed under a Creative Commons Attribution 4.0 International License. Read Full License 


\section{Abstract}

\section{Background}

ESD is the gold standard treatment for large sessile adenomas yet US adoption rates are low. In ESD, tissue is cut only when the scope tip, with hot knife extended, is moving; this requires different skills than needed for snare polypectomy (scope tip held still). Scope tip control and ESD training methods are needed. A program including an inanimate figure tracing model (FTM; Model1), ex vivo pig stomach model (PSM; Model2) and bovine colon model was devised. This paper concerns preliminary results for models 1 and 2 .

Methods

A straight hollow plastic tube with a window cutout $15 \mathrm{~cm}$ from its end was used for both models (slotted sponge $=$ "anus"). For the FTM a paper with a line figure is placed in the window. After endoscope insertion and positioning the figure is traced with a catheter "pen"; 8 tracings ( 4 figure types) and 1 pig ESD were done per session. In the PSM a piece of pig stomach and Bovie pad was placed over the window. After "lifting" the mucosa ESD resection of a "polyp" was done. Time/accuracy were tracked for both models as were bowel wall injuries in the PSM.

Results

A total of 30 FTM sessions and PSM cases were done (2 trainees). Completion times and accuracy improved over 8 FTM sessions for less experienced trainee A but not for trainee B. A total of 29/30 PSM cases were completed. The number of deep muscle injuries decreased with time, however, case length correlated with tissue quality and not number of cases. Lifting and tissue conductivity problems were noted in poor quality tissue.

\section{Conclusions}

Despite model related issues, both models are feasible and allow trainees to learn scope tip control and ESD; clearly, more study is needed. A smaller diameter tube and use of fresh stomach are advised.

\section{Background}

ESD is the gold standard as regards the definitive treatment of large sessile adenomas of the colon. ${ }^{1-4}$ The en bloc removal of benign neoplasms is certainly preferable to piecemeal excision since it permits pathologic assessment of the lateral and deep resection margins to ensure a complete resection. In the case of superficial T-1 cancers removed via ESD, the ability to determine the depth of submucosal invasion has allowed patients with sm1 cancers (invasion < 1000 microns) to avoid colectomy in Japan since the survival rates of ESD alone vs colectomy are comparable. ${ }^{5-8}$ Thus far, the adoption rate of ESD in the US is low, largely because the skills required are hard to acquire and distinct from the skill set of the great majority of American endoscopists. 
Endoscopic mucosal resection (EMR), the method most commonly used in the US to remove large polyps, is uniformly performed with the scope tip in the stationary position after which the snare is pushed out from the tip, the polyp encircled and the snare closed and power applied. The snare moves during this process but the scope shaft and end remain motionless. In contrast, with ESD, in order to cut tissue the scope tip must be in motion with a hot needle knife protruding. This is a fundamentally different approach that demands precise control of the moving scope tip to follow a precise path while cutting tissue. With poor tip control the knife may injure the adjacent bowel wall or perforate the bowel.

ESD methods were developed in Japan to definitively treat early gastric neoplasms which are common in the Far East. After gastric ESD was fully ensconced, endoscopists begin utilizing ESD methods in the large bowel which is more challenging because the bowel wall is notably thinner and the colon longer, narrower, and not fixed in position. The Japanese approach to ESD training and clinical application has been and remains centered on the stomach. Today, in most Japanese centers, a trainee must complete 40 to 60 gastric ESD cases before being allowed to perform colonic ESD. In the U.S. the incidence of gastric cancer is quite low, thus, American endoscopists cannot learn ESD by removing stomach neoplasms.

The absence of a reasonable ESD teaching model to substitute for gastric cases is a major reason why ESD adoption rates in the US are quite low. For the vast majority of endoscopists, it is not reasonable or practical to learn colonic ESD in the clinical setting. A training strategy centered on the colon is needed that will allow endoscopists to learn ESD methods in a reasonable amount of time. Although ex vivo animal models have been used worldwide as a means of introducing doctors to ESD ${ }^{9-12}$, with few exceptions, they have not been used as the primary training tool. ${ }^{13}$ It is the authors' contention that if enough ESD "cases" (40-60) were done using inanimate and ex vivo training models that it would be possible to substitute these cases for the human gastric cases that, in Japan, are required prior to attempting colonic ESD in patients.

The proposed program consists of three models: 1) an inanimate figure tracing model, 2) an ex vivo pig stomach model and 3) an ex vivo bovine colorectal model. The figure tracing model teaches trainees how to control the moving scope tip with an instrument protruding. The trainee traces line figures on a paper inserted into a hollow plastic tube using a modified sclerotherapy needle/pen. In the second model, an actual ESD is done on a piece of pig stomach placed inside the same plastic tube. The initial 15-20 sessions include both figure tracing and stomach ESD. The third model which utilizes bovine large bowel (intact 2.5-3 feet long colon, rectum, and anus) is more realistic and challenging (insufflation is required; "polyp" location and colon configuration can be changed). It is advised that 20 or more complete ESD bovine "cases" be done.

This paper presents the first two training platforms. What follows are descriptions and explanations of the models, preliminary results, and a critique of the methods.

\section{Materials And Methods}


Pig stomachs were used in this study with approved exemption form Institutional Animal Care and Use Committee (IACUC) [IACUC\#: 2016-0007], Icahn School of Medicine at Mount Sinai, New York, USA.

Endoscopy platform and associated equipment: An endoscopic tower and endoscope dedicated solely to training is needed. Clinical equipment cannot be used for ex vivo animal models and vice versa. Although a pediatric colonoscope is ideal, an adult colonoscope or upper scope will also suffice. Neither the figure tracing nor ex vivo pig models require insufflation since a hollow plastic tube serves as the colon. Suction is helpful but not mandatory for the pig model.

Plastic "colon" tube: A hollow plastic tube with a diameter of $6.5 \mathrm{~cm}$ and length of $30 \mathrm{~cm}$ served as the "colon" for both models. Smaller diameter tubes can also be used. A rectangular portion of the wall (recommended dimension $6 \times 5 \mathrm{~cm}$ ) is cut out with the distal edge of the window located $15 \mathrm{~cm}$ from the "anal" end of the tube.(Fig. 1) The colon tube is affixed to a rectangular hard "peg" board $(45 \mathrm{~cm} \times 55 \mathrm{~cm})$ using adjustable circular vise grips that are anchored to the board with zip ties via the board's small holes.(Fig. 2) The plastic tube is placed in the center of the board such that the "anal" end of the tube is several inches from the board's edge. Since ESD is best done with the polyp in the "up" position (to employ gravity as a retractor), the window cutout should face the ceiling. Circular pieces of sponge with a diameter slightly larger than the tube's internal diameter are cut from larger sponges and placed at each end of the tube after being soaked in water. An incision is made at the center of the sponge at the tube's anal end to permit endoscope insertion. If desired, a longer plastic tube that can be bent into an $\mathrm{S}$ or $\mathrm{L}$ shape can be used and the window cutout placed further away from the "colon's" end to increase the difficulty.

Figure Tracing Model: Rectangular pieces of blank paper (dimensions a bit smaller that the window cutout) with a shape or line figure on it are mounted on index cards or rectangular pieces of thin cardboard (dimensions larger than the window) and then placed over the window cut out so that the paper side faces the lumen. The window insert is held in place with tape or several rubber bands that encircle the plastic tube.(Fig. 3) At each training session the trainee would trace the following set of line figures once or twice: 1) a grid of horizontal and vertical lines, 2) an "S" shaped line, 3) a circle, and 4) a figure of 8.(Fig. 4)

A sclerotherapy catheter is used as the "pen" in this model. The needle is left in the retracted position and a small piece of cotton inserted into the catheters tip. A dilute solution of methylene blue serves as the "ink" and is periodically injected into the catheter via a syringe affixed to the outer end. (Fig. 5)

The trainee begins the exercise by inserting the colonoscope into the model and torquing the scope shaft and deflecting the control wheels such that the scope's tip is positioned parallel and tangential to the window cut out. (Fig. 6) This will place the target in the down position on the monitor. This is the only orientation that will allow the pen to be used while maintaining a view of the target. The ink primed sclerotherapy catheter is then inserted into the scope and the tip extended a short distance from the scope tip. The cotton plug in the catheter tip acts as a wick that absorbs the "ink". When the moving catheter touches the paper a line is made. Periodically, more ink is injected into the catheter. The trainee 
traces the figure with a timer running. When complete the timer is stopped and the paper is removed and replaced with another figure insert. This is repeated until all figures have been traced.

Initially one set of figures are traced per session. As the trainee's skills improve, a second set of figures may be done. After becoming proficient tracing the figures in one direction (left to right on the grid or clockwise on the circle, 8 , or S figure) it is recommended that figures be traced in the opposite direction. The completed tracings are scored. The parameters tracked are: 1) time, 2) number of pen strokes (separate lines) needed to complete the tracing, and 3) the number of deviations more than $2 \mathrm{~mm}$ from the line and 4) the number of gaps between line strokes.

Pig Stomach Model: In addition to the above mentioned equipment the following items are needed: 1) pig stomach, 2) high frequency electrosurgical generator, 3) needle knife(s), 4) sclerotherapy catheter, 5) lift solution with dye, and 6) electrocautery pads. In addition, one or 2 assistants are needed to make the lift injections, refill the lift solution syringes, control the needle knife, adjust the energy device, and assist in the exchange of instruments.

Fresh refrigerated porcine stomach is preferable to frozen tissue. The stomach is cut open, cleaned in a sink with cold water and then laid flat. The "polyp" is then created via a marking pen, dye injection, or surface "branding" in the distal fundus and/or proximal body of the stomach. The brand is the recommended method. A large paper clip is straightened and a 2 to $3 \mathrm{~cm}$ circular loop fashioned at one end: the opposite straight end serves as the handle. The loop is heated over a candle and then applied to the mucosal surface. (Fig. 7) This should create a durable superficial black tattoo or brand (may need several burns). Next, full thickness rectangles of the wall $(9 \times 8 \mathrm{~cm})$ are harvested from the stomach pelt. (Fig. 8)

The stomach rectangle is then placed, serosal side down, onto the sticky surface of a electrocautery pad. The pad and stomach are then placed over the window cutout of the hollow plastic tube (cutout in up position). (Fig. 9) The pad and stomach are held in place with several previously placed rubber bands that encircle the tube. The Bovie pad is then connected to the electrocautery machine (Fig. 10).

The colonoscope, with clear dissection cap attached, is then inserted via the "anal" end of the tube and positioned so that the tip is tangential to the lesion. The sclerotherapy catheter is then inserted through the scope and into the bowel wall adjacent to the target and lift solution injected to establish a mucosal lift (video clip 1). A needle knife is then inserted via the instrument channel and the ESD begun. The mucosal lift is refreshed as necessary and the detachment continued until the lesion has been fully detached.

Although not the focus of this paper, the steps involved in ESD are: superficial mucosal marking of planned resection line (video clip 2), mucosal incision for $15-20 \%$ of the lesion's circumference (video clips 3,4$)$, undermining the cut edge to create a submucosal pocket, cap dissection beneath the lesion (video clips 5,6), extension the mucosal incision another $15-20 \%$ of the circumference, periodic lift reinjection (video clip 7) and repetition of the above steps. ${ }^{14}$ Once the lesion is sufficiently detached, gravity facilitates the completion of the resection by "retracting" the partly detached "polyp" downward (video clip 8).

After the ESD has been completed the resected specimen and the mucosal defect on the patch of stomach are assessed (Fig. 11) and the results and findings recorded on a scoring sheet. The following 
parameters are tracked: total resection time, specimen integrity (including margin measurements), number of partial and full thickness muscularis propria injuries, serosal integrity, pig tissue quality, number of sclerotherapy catheter insertions and lift injections, ease of lift establishment and maintenance, total time needle knife was engaged, and total effective cutting time (when the knife actually cut tissue).

\section{Results}

Preliminary results of two trainees will be presented followed by a description of the model-related problems noted. Two colorectal attending surgeons served as the trainees. Trainee A, who had no prior EMR or ESD experience, did 8 combined figure tracing and pig stomach ESD sessions. Trainee $B$ who has been utilizing EMR and ESD methods in conjunction with laparoscopy for 8 years did 16 combined figure tracing and pig stomach ESD sessions as well as additional 6 pig ESD cases.

In reference to the figure tracing model, as regards Trainee A's results, the impact of practice was clear. The time required to complete all 4 figures decreased with experience.(Figs. 12,13) Close examination of the drawn figures as regards number of pen strokes needed to complete each figure, the number of gaps between lines, and deviations from the line demonstrates that, in general for Trainee $A$, increased experience was associated with improved results.(Figs. 14, video clips 9,10) As regards Trainee B's results, there was no decrease in the completion times.(Fig. 15) However, the completion times for the last 8 sessions were more consistent and the range of times notably smaller when compared to the first 8 sessions. Also, as regards the number of lines needed to complete each figure or the number of gaps and deviations for trainee $B$, there was no clear change over time (Fig. 16). It is important to note, when comparing Trainee $A$ and $B$, that the initial completion times where shorter for trainee $B(60-80$ percent shorter for $3 / 4$ figures) (Fig. 17). Also, from the start, there were notably fewer gaps, deviations, and lines required to complete the figures for Trainee $B$ who had considerable ESD/EMR experience.

In regards to the pig stomach ESD results ( $n=30$ with full data), 29 cases were completed (in the final case, with a $3 \mathrm{~mm}$ tissue attachment remaining, the pig stomach fell off the bovie pad into the model which ended the procedure). The mean case duration was 62.6 minutes (range 32.5-98.1 minutes). The mean margin (distance from edge of the resected specimen to the "polyp") was $3.0 \mathrm{~mm}$ (range 0$15 \mathrm{~mm}$ ). The mean number of full thickness bowel wall injuries was $0.9 /$ case (range $0-5$ ) and the mean number of partial thickness injuries was 4.5 /case (range $0-14$ ). The number of full and partial thickness injuries per case decreased with experience (Figs. 18-21). The mean number of sclerotherapy catheter insertions to establish/maintain the lift was 5.1/case (range 1-10) and the mean number of actual mucosal injections was 17.3 /case (range 4-27). The mean amount of time needed for making/maintaining the lift was 5 minutes 52 seconds (range 2-19 minutes). The mean amount of time required for all instrument exchanges (knife out, sclerotherapy needle in, etc.) was 7 min 21 seconds. The total time required to position the scope tip and needle knife prior to each cut was 27 minutes 25 seconds ( $44 \%$ of case time); thus, almost half the case was spent manipulating the scope into position. Current was applied to the needle knife for an average of 16 minutes and 5 seconds per case, however, $45 \%$ of the time this did not result in effective tissue cutting due to conductivity issues. 
There was no association noted between number of cases and length of ESD procedure (Figs. 22,23). Of note, tissue quality varied considerably from stomach to stomach and, as shall be shown, likely influenced case duration. A good number of the stomachs were stored frozen prior to use; it is our strong impression that the freeze thaw process impacts mucosal integrity. Whereas in good quality tissue a mucosal lift could readily be established, in poor quality stomachs it was invariably difficult to obtain and maintain a lift. In some poor quality specimens there were mucosal gaps or pores that would immediately leak when an injection was made; also rapid leakage via the puncture site was noted. In some cases it was not possible to establish an enduring lift; regardless, the ESD cases were completed. Thus, the lift duration and the ability to refresh a lift directly correlated with tissue quality. The stomachs were obtained from a variety of sources based on availability; the tissue quality from late sources was, in general, poor. When the ESD cases are divided into 3 groups chronologically (data available for 28 cases) the proportion of pig stomachs judged to be poor quality increased notably from the initial 8 cases (25\%) to the middle 11 cases (36\%) and the final 9 cases (70\%). The mean case times for the early, middle, and late cases was 40,63 , and 88 minutes, respectively. Of note, when the 3 groups of cases were considered in order there was a stepwise increase in total knife time (9.8, 14.8, and 19.8 minutes) and amount of time wasted in ineffective cutting $(2.6,7,9.8$ minutes). The same trend was observed when the mean time required for instrument changes (knife out, sclerotherapy catheter in) per case is considered (first cases, 3.8 min.; middle third 6.4 min; last third, 9 minutes).

Tracing Model Issues: It proved difficult to accurately score the tracing if too much ink was injected which caused a very wide line, blotch, or a hole in the paper; too little ink resulted in a very faint line (video clip 11). Also, it was noted that the pen tip sometimes got caught momentarily on the paper while the scope tip was being moved around the figure; this resulted in a skipping movement of the pen that decreased the accuracy somewhat and caused ink blotches.

Another problem noted was that with the pen extended an appropriate distance from the scope it was sometimes hard to touch the paper. A related problem was that, at times, the only way to get close to the figure was to sharply deflect the end of the scope which resulted in an acute angle between scope tip and the figure (a tangential position is preferred). This made it harder to finely control the scope's movements. The large diameter of the plastic tube used for these studies may be the cause of these problems. To position the scope so that the colon wall target is at the bottom of the endoscopic image (the only orientation that allows an instrument to be used while maintaining a view of the pathology) the distal scope shaft must be torqued and the tip bent by turning the deflection wheels (of note, it is the distal 10$12 \mathrm{~cm}$ of the colonoscope shaft that bends in response to wheel deflection). When the end of the scope is bent sharply the main straight part of the scope shaft is pushed into the opposite wall of the "colon" tube. The tube's wall resists further lateral movement and, thus, stabilizes the shaft's position which allows the distal scope to be further bent such that it bridges the diameter of the tube. The larger the "colon" diameter, the greater the distance that must be bridged and the more acute the final angle between the distal tip and the target's surface. Also, despite these maneuvers the scope tip may still remain a good distance from the target which necessitates extending the "pen" further from the tip. The acute angle and 
the long pen extension make fine control the tips movement difficult. The use of a smaller diameter tube may eliminate or lessen this problem.

It was also noted that the paper and figure, once positioned, often sat in a sunken position below the inner surface of the tube (video clip 8). This further increases the diameter of the tube which, as mentioned above, makes ideal positioning of the scope more difficult. This can be remedied by placing a thick piece of paper or thin cardboard between the index card and the paper to raise the level of the paper to the tube's inner surface and eliminates the depression.

Pig Stomach Model related issues: As mentioned, tissue quality was an important factor. Tissue integrity and quality impacted the following parameters: ability to establish and maintain a mucosal lift, number of catheter insertions and injections, ability to find the submucosal plane, conductivity, effectiveness of needle knife in cutting tissue (video clip 12), and number of muscle injuries and perforations. Independent of tissue quality, the ability to maintain contact between stomach wall and bovie pad such that the current will effectively flow varied from the start to the finish of a case and from colon to colon. As mentioned above, at times, it proved extremely difficult, presumably due to conductivity issues, to cut tissue despite good contact between knife and tissue.

Also, even in a reasonable quality colon it proved difficult to maintain a lift. The fluid may leak out immediately after the mucosa is incised. Also, at times, it was very difficult to re-establish a lift that lasted more than 30-60 seconds. A variety of lift solutions were tried (Albumin, Hyaluronate, Saline, and Eleview); none appreciably increased the lift retention time after the mucosa was incised. Making and maintaining a submucosal lift was the single greatest problem encountered. Finally, similar to the tracing model situation, at times, the large diameter of the plastic tube made it necessary to sharply angle the scope and extend the knife further than usual to reach the target. Under these conditions it took longer to position the scope (more maneuvering required) and to cut tissue (poor tip control).

\section{Discussion}

The results and experience of 2 trainees using the figure tracing and porcine stomach models, presented above, demonstrate that both models are feasible and provide the opportunity to improve scope tip control skills and to perform ESD. It is not possible to draw firm conclusions because of the small sample size. Further, the ESD training program, outlined in the introduction, includes a 3rd model that utilizes ex vivo bovine large bowel; a separate paper regarding this model will soon be submitted. It is important to realize that a critical requirement of this training approach is repetition. Only by rigorously "training" will the necessary skills be acquired. These models merely provide opportunities to practice and to learn a new set of skills. The outcome that will be the final arbiter of this 3 model program is whether graduating trainees are adequately prepared to start doing clinical ESD cases. Preliminary results suggest that the answer is yes, however, this cannot be conclusively stated presently. Let us examine the results, to date, of the first two models. 
The goal of the figure tracing model is to improve scope tip control skills which are of critical importance in ESD where only by moving the scope tip with a hot needle knife protruding can the mucosa and submucosal attachments around and beneath the lesion be divided. This is fundamentally different from the snare technique which simply strangles and cooks the entrapped tissue. The act of pushing a "pen" around a figure is very similar to cutting along a precise line with a knife. Trainee A's results suggest that for endoscopists with limited or no experience with ESD or EMR that scope tip control can be demonstrably improved after 8 sessions; with practice the figures were more rapidly completed and the accuracy improved. Of note, Trainee B's results suggest that once the skill set reaches a certain level that it is harder to document incremental improvement with this model. Trainee $B$, who had been doing EMR and attempting ESD for years, came into the model with more experience as reflected in the notably shorter first session completion times (vs Trainee A)(Fig. 15). The authors' believe that model related issues (difficulty touching pen to paper, acute angle between scope tip and figure, and "ink" issues) make the model less sensitive at higher skill levels. This is reflected in the less than conclusive time results and other outcomes for Trainee B. Despite the limitations, it was both trainees impression that these sessions improved their control skills.

As regards the pig stomach model, it proved possible to complete the ESD disc excision in 29/30 cases; the entire "polyp" was excised in all but 1 case. The margin of normal tissue varied from $0-15 \mathrm{~mm}$ and was at least $1 \mathrm{~mm}$ for all but a few specimens. The number of muscularis propria injuries (partial and full thickness) decreased with experience for both trainees (Figs. 18-21); this result suggests that the trainees' skills improved over time. Of note, case length did not trend downward with experience (Figs. 22,23). Also noteworthy and indicative of the difficulty of ESD in general is that $44 \%$ of the case time was used simply to manipulate the scope into position (orientation of instrument channel to tissue surface) to cut tissue. Interestingly, tissue quality was the parameter that best correlated with case length. In stomachs with poor tissue integrity it took considerably longer to establish/maintain the lift, to cut tissue (due to increased conductivity issues), and, at times it was necessary to do significant portions of the ESD with minimal or no lift at all. For inexplicable reasons, the proportion of poor quality stomachs increased as the study proceeded. Poor tissue quality and conductivity routinely added 10-20 minutes to the case length which likely obscured incremental gains in ESD skills that might otherwise shorten the case. It is important to note that a substantial proportion of the ESD cases were completed under circumstances that would not be tolerated in the clinical setting. The ability to complete ex vivo cases, regardless of model and tissue related issues is actually a key attribute of ex vivo models.

Porcine tissue (stomach, esophagus, and colon), both ex vivo and in vivo, has been used for training by a other centers $^{9-12}$, however only 2 other investigators have suggested that trainees perform a large number of pig cases. ${ }^{13}$ The figure tracing model is unique. These 2 models provide the opportunity to learn new skills and to practice them. The alternative to ex vivo and inanimate model training is to learn in the clinical setting. As mentioned, early stomach cancers are rare in the US which means that ESD training must be done in the colon. In the clinical arena, because of limited case volume and concerns for patient safety, it would be difficult or impossible for an endoscopist to get a comparable colonic ESD 
experience in the same time frame. In 6 months the trainees did 30 cases; in the clinical arena it would take several years or longer to accrue this volume. Further, it is likely that a substantial number of early human ESD cases would be abandoned mid case in favor of EMR or a bowel resection if a deep muscularis propria injury were made or the lift could not be maintained. As mentioned, a major advantage of ex vivo ESD models is that the case can almost always be finished. The ability to complete ESD cases and to learn the approach options for a half excised polyp provides trainees with the experience to deal with the unique problems and dilemmas that may arise late in a case. Also, the opportunity to perform many cases in a compressed time frame allows trainees to start ESD cases from different points along the polyp's circumference. The resection can be started at the distal aspect after which the lateral border is incised followed by the proximal side or the case can be begun proximally or laterally. Higher case volume also allows trainees to alter the time interval between lift reinjections and learn how that impacts case progression. Similarly, experience can be gained with cap dissection. In short, favorite and alternative case strategies can be developed before clinical cases.

In doing this study it became apparent that not all "stable" bowel wall lifts are submucosal; sometimes the deeper layers of the wall may expand upon injection. The reason for this is that the sclerotherapy needle invariably needs a strong push to penetrate the mucosa. The required forceful shove often places the needle tip in either the muscularis propria or the subserosal layers of the wall. Thus, when the lift injection is begun and the catheter slowly withdrawn in search of the submucosal plane, the needle tip is in the deep wall. Depending on how much fluid is injected either the muscularis propria or subserosal planes can expand and lift the mucosal layer. In the presence of "deep wall" lift it will be very hard to enter and stay in the non-expanded submucosal layer which is very thin.

Several model modifications are recommended based on this study. First, a smaller diameter hollow plastic tube that better approximates the human colon should be used for both the figure tracing and pig stomach ESD models. As mentioned, the diameter of the tube alters the handling characteristics of the scope and dictates, in some situations, the angle between the scope tip and the target surface. Also, the paper figure to be traced should be mounted on cardboard so that when placed in the window cutout the paper is at the level of the tubes inner surface (vs a depressed hollow). Finally, fresh pig stomach that has not been frozen should be used, if possible.

In summary, it is very difficult in the US to learn ESD methods according to the Japanese paradigm because there are few gastric neoplasms. It is also difficult for the novice to learn by doing colon cases because the chances for perforation or incomplete excision are high and the case volume of large polyps for most endoscopists is such that it would take years to do an adequate number of cases. It is proposed that ESD methods can be learned by doing a large number of cases using an inanimate figure tracing model, an ex vivo porcine model and a bovine large bowel model as presented in the introduction. This preliminary report regarding the first two models suggests that scope control and ESD skills can be acquired in this manner. Obviously, the impact of the third model's results needs to be determined and additional trainees will need to complete the entire program. In the end, the final arbiter will be the trainees' clinical ESD adoption rate for colonic polyps. 


\section{Abbreviations}

ESD:Endoscopic Submucosal Dissection, EMR:Endoscopic Mucosal Resection, FTM:Figure Tracing Model, PSM:Pig Stomach Model

\section{Declarations}

\section{Disclosure Statement:}

Olympus Corporation loaned the endoscopy equipment, to our lab, for this investigator initiated study. The equipment has been returned. Olympus had no input into the design, execution or interpretation of the study results.

Dr. Whelan is a speaker and consultant for the Olympus Corporation and a speaker for Ethicon Endosurgery.

Drs. Abhinit Shah MD, Erica Pettke MD, Elie Sutton MD, Geoffrey Bellini MD, Jaspreet Sandhu MD, Carl Winkler MD, Xiaohong Yan PhD, Vesna Cekic RN, HMC Shantha Kumara PhD and Nipa Dilip Gandhi MD have no conflicts of interest or financial ties to disclose except as mentioned above regarding loaned equipment.

\section{Acknowledgements:}

This study was made possible by a generous donation from the Wade Thompson Foundation to the Division of Colon and Rectal Surgery, Department of Surgery, Mount Sinai West Hospital, New York.

\section{Funding:}

This was supported by Mount Sinai West Hospital, Department of Surgery, New York; donation funds.

\section{Availability of Data and materials:}

All data generated or analyzed during this study are included in this published article.

\section{Ethical approval and consent to participate;}

This manuscript describes the advanced endoscopic procedure called ESD (endoscopic submucosal dissection). No human or live animal model was involved in this study. Study was conducted with approved exemption from Institutional Animal Care and Use Committee (IACUC) [IACUC\#: 2016-0007], Icahn School of Medicine at Mount Sinai, New York, USA.

\section{Author contributions:}


AS , EP and JS contributed to the conception, design and statistical analysis ES,GB,CW, XY and HMCSK; study design, sample preparation, data collection, analysis and interpretation; NG and RLW contributed to the conception, conduction of experiments, interpretation of data and critical revision of the manuscript. All authors involved in drafting the manuscript, made revisions and approved the final version of the article to be published.

\section{References}

1. Deprez PH, Bergman JJ, Meisner S, Ponchon T, Repici A, Dinis-Ribeiro M, Haringsma J (2010) Current practice with endoscopic submucosal dissection in Europe: position statement from a panel of experts. Endoscopy42:853-58

2. Cao Y, Liao C, Tan A, Gao Y, Mo Z, Gao F (2009) Meta-analysis of endoscopic submucosal dissection versus endoscopic mucosal resection for tumors of the gastrointestinal tract. Endoscopy41:751-7.

3. Saito Y, Fukuzawa M, Matsuda T, Fukunaga S, Sakamoto T, Uraoka T, Nakajima T, Ikehara H, Fu KI, Itoi T, Fujii T (2010) Clinical outcome of endoscopic submucosal dissection versus endoscopic mucosal resection of large colorectal tumors as determined by curative resection. Surg Endosc24:343-52.

4. Saito Y, Uraoka T, Yamaguchi Y, Hotta K, Sakamoto N, Ikematsu H, Fukuzawa M, Kobayashi N, Nasu J, Michida T, Yoshida S, Ikehara H, Otake Y, Nakajima T, Matsuda T, Saito D (2010) A prospective, multicenter study of 1111 colorectal endoscopic submucosal dissections (with video). Gastrointestinal endoscopy 72: 1217-25.

5. Lee EJ, Lee JB, Lee SH, Kim DS, Lee DH, Lee DS, Youk EG (2013) Endoscopic submucosal dissection for colorectal tumors-1,000 colorectal ESD cases: one specialized institute's experiences. Surg Endosc. 27:31-9.

6. Kim JH, Baek IH, Kim KO, Jang HJ, Baik GH, Lee CK, Min KW (2016) Usefulness and feasibility of endoscopic submucosal dissection for colorectal tumor: a nationwide multicenter retrospective study in Korea. J Gastrointest Oncol. 7:924-30.

7. Asayama N, Oka S, Tanaka S, Hayashi N, Arihiro K, Chayama K (2015) Endoscopic submucosal dissection as total excisional biopsy for clinical T1 colorectal carcinoma. 91:64-9.

8. Tanaka S, Terasaki M, Kanao H, Oka S, Chayama K (2012) Current status and future perspectives of endoscopic submucosal dissection for colorectal tumors. Digestive Endoscopy24:73-9

9. Hon SSF, Ng SSM, Lee JFY, Li JCM, Lo AWI (2010) In vitro porcine training model for colonic endoscopic submucosal dissection: an inexpensive and safe way to acquire a complex endoscopic technique." Surg endosc24:2439-43

10. Uraoka T, Parra-Blanco A, Yahagi N. (2013) Colorectal endoscopic submucosal dissection: is it suitable in western countries? Journal of gastroenterology and hepatology28:406-14.

11. Parra-Blanco A, Arnau MR, Nicolás-Pérez D, Gimeno-García AZ, González N, Díaz-Acosta JA, Jiménez $A$, and Quintero E (2010) Endoscopic submucosal dissection training with pig models in a Western 
country. WJG16:2895-900

12. Berr F, Ponchon T, Neureiter D, Kiesslich T, Haringsma J, Kaehler GF, Schmoll F, Messman H, Yahagi N, Oyama T (2011) Experimental endoscopic submucosal dissection training in a porcine model: learning experience of skilled Western endoscopists. Digestive Endoscopy23:281-9

13. Pioche M, Rivory J, Aguero-Garcete G, Guillaud O, O’Brien M, Lafon C, Reversat N, Uraoka T, Yahagi N, Ponchon T (2015) New isolated bovine colon model dedicated to colonic ESD hands-on training: development and first evaluation. Surg endosc 29:3209-15.

14. Whelan RL (2011) Laparoscopic-Facilitated Colonic Endoscopic Mucosal Resection and Endoscopic Submucosal Resection of Adenomas: Techniques to Avoid Segmental Colectomy.J Gastrointest Surg 15:1309-12.

\section{Supporting Videos}

Video 1: Insertion of Sclerotherapy Catheter, injection of fluid, establishing mucosal lift

Video 2: "Marking" the planned incision

Video 3: Making the mucosal incision

Video 4: Extending the incision before undermining the edge

Video 5: Undermining the lesion, ready for cap dissection

Video 6: Creation of submucosal pocket, performing cap dissection

Video 7: Re-establishing lift

Video 8: Importance of position of the lesion- gravity facilitates completion of resection

Video 9: Before and After results of Trainee A's tracing of "figure of 8"

Video 10: Before and After results of Trainee A's tracing of "grid pattern"

Video 11: The "ink" problem with the Figure Tracing Model

Video 12: Poor tissue quality- failure of the tissue to cut despite cauterization

\section{Figures}




\section{Plastic Colon Model}

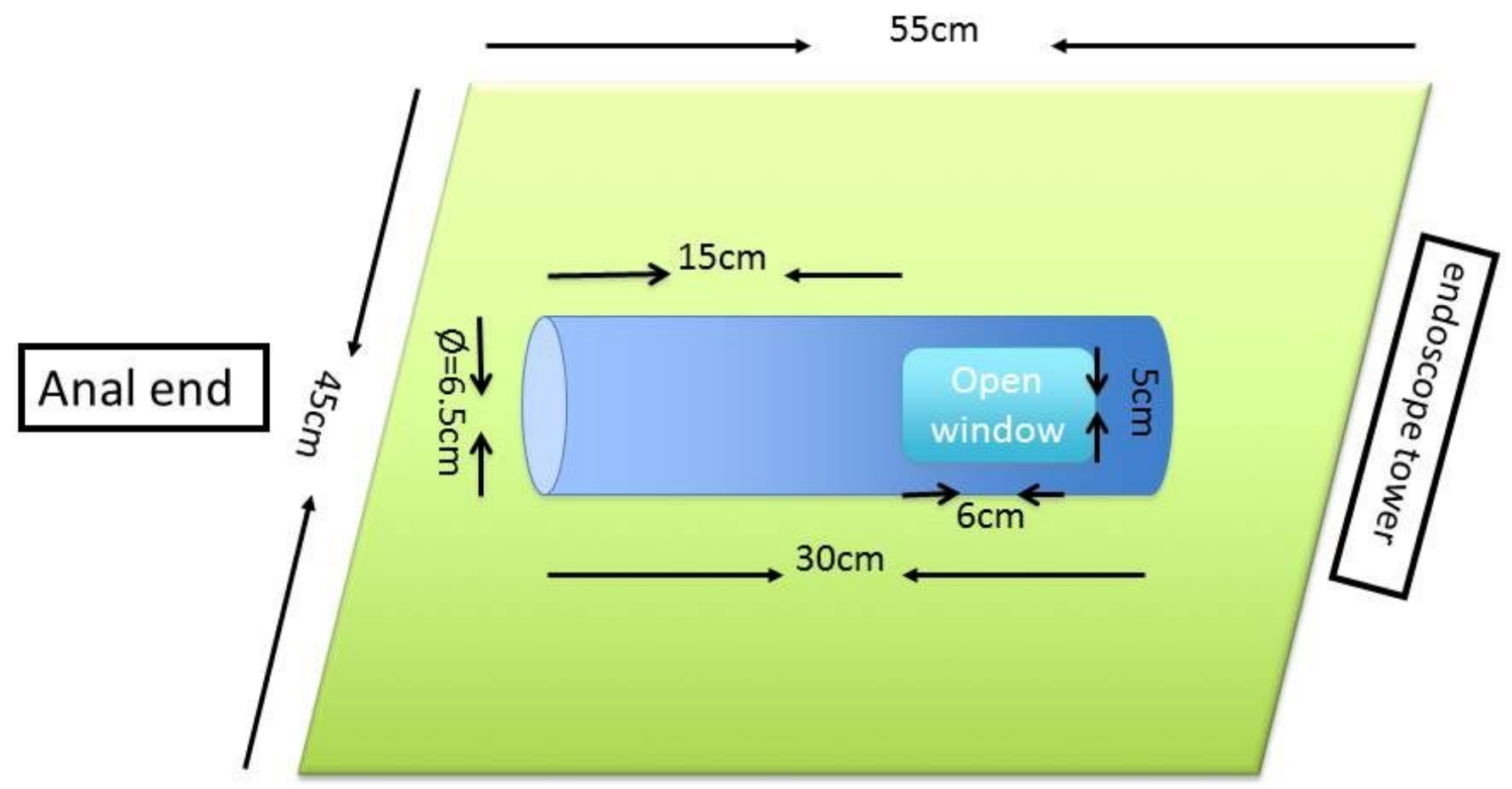

Figure 1

Figure 1

Design of the plastic "colon" tube with recommended dimensions. 


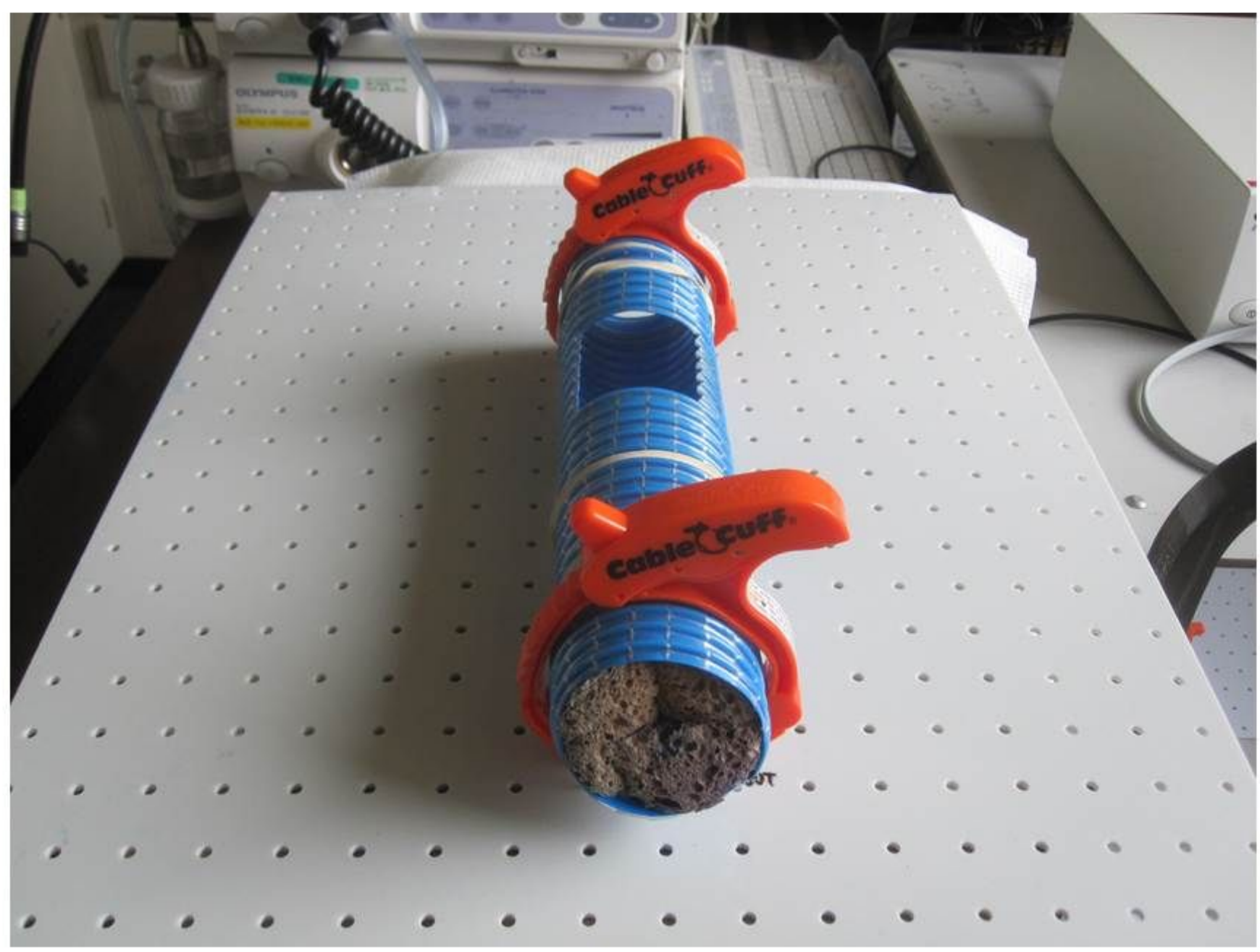

Figure 2

Figure 2

Colon tube fixed to the peg board. Notice the "anal" end of the tube, and the cut-out window. 


\section{Applying the Pattern to Tube}
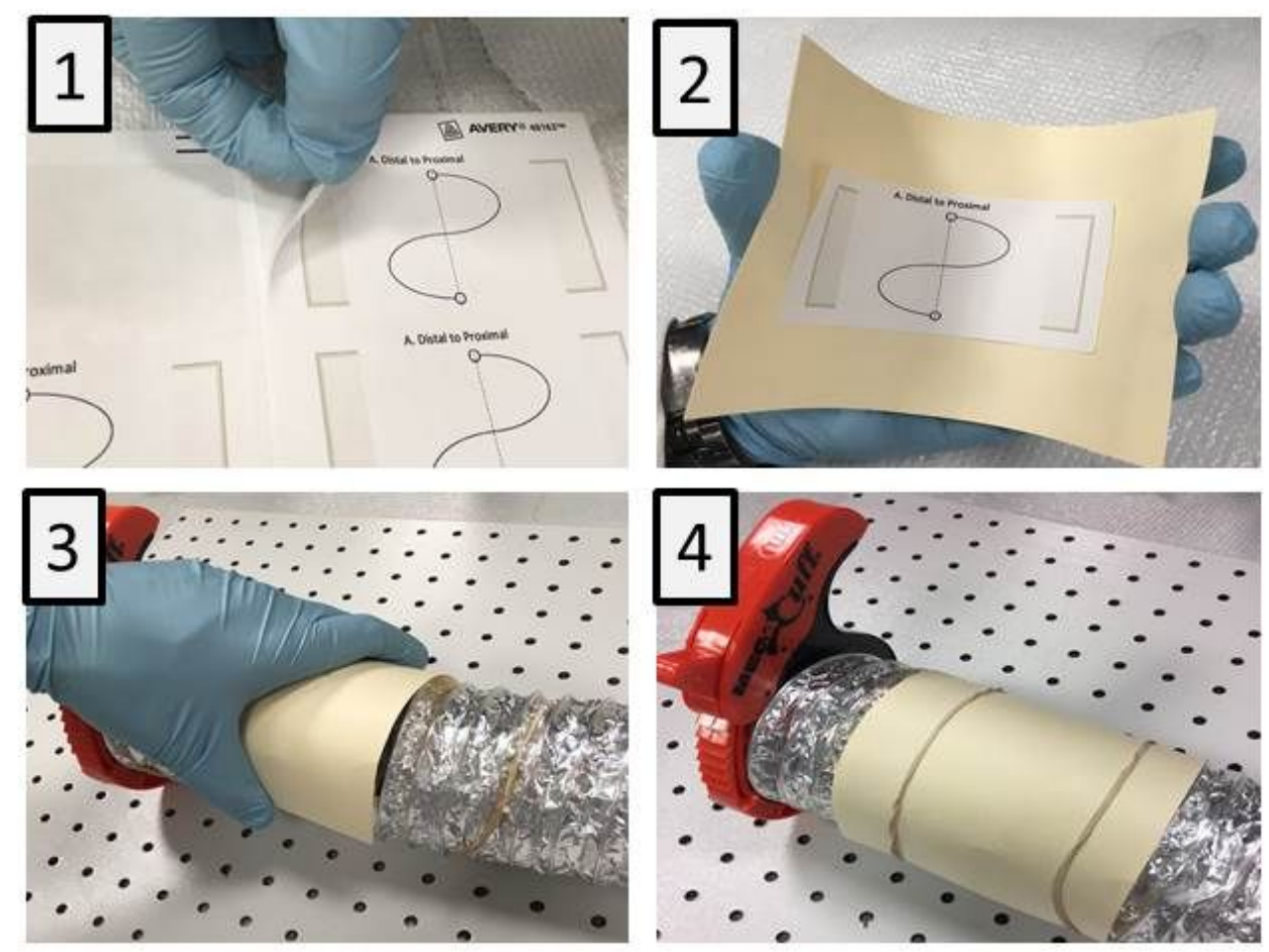

Figure 3

Figure 3

Placement of an "S" shaped figure over the cut-out window. 


\section{Endoscope Pattern Tracing}
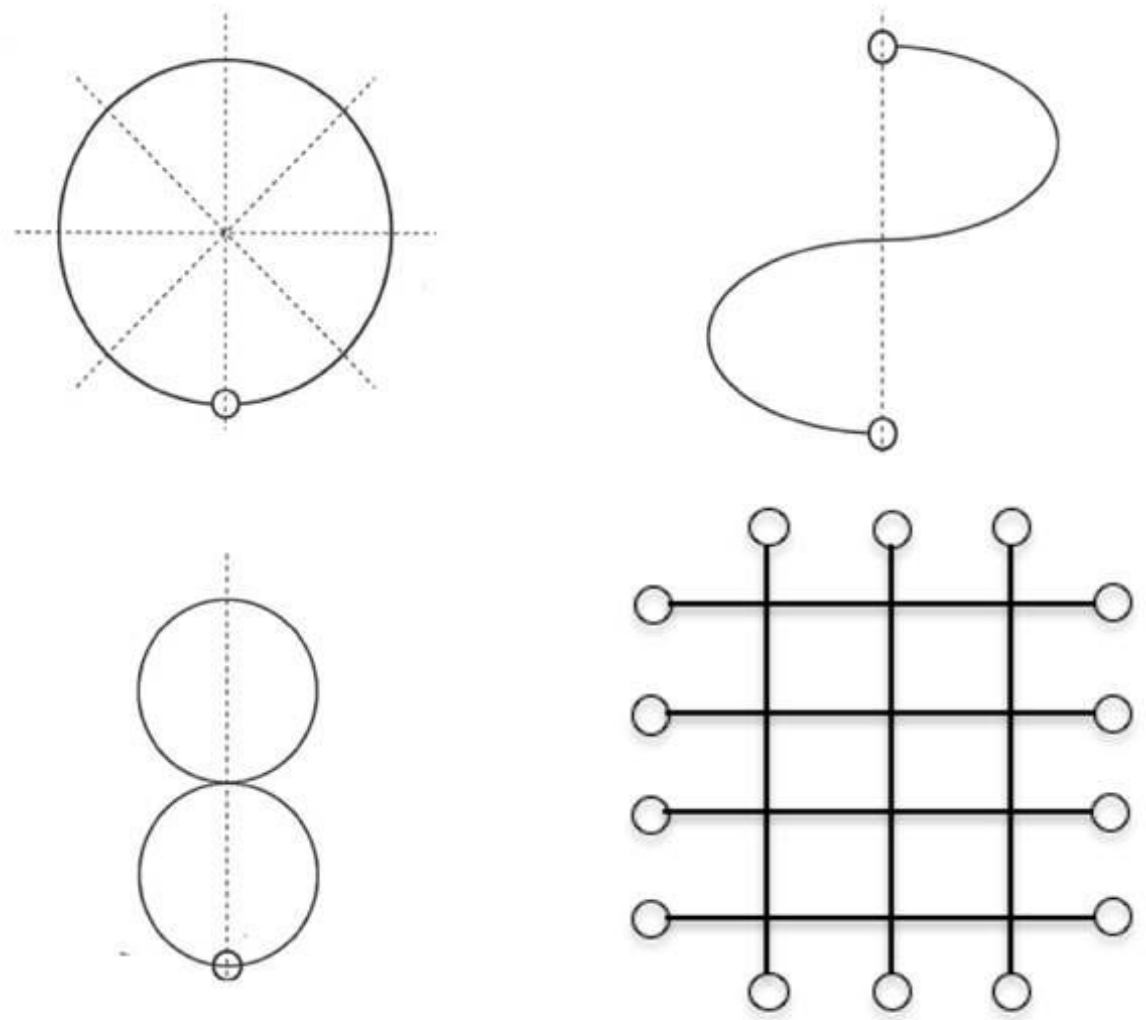

Figure 4

Figure 4

Sets of figures used for tracing. 


\section{Tracing Pen with Catheter and Syringe Attached}

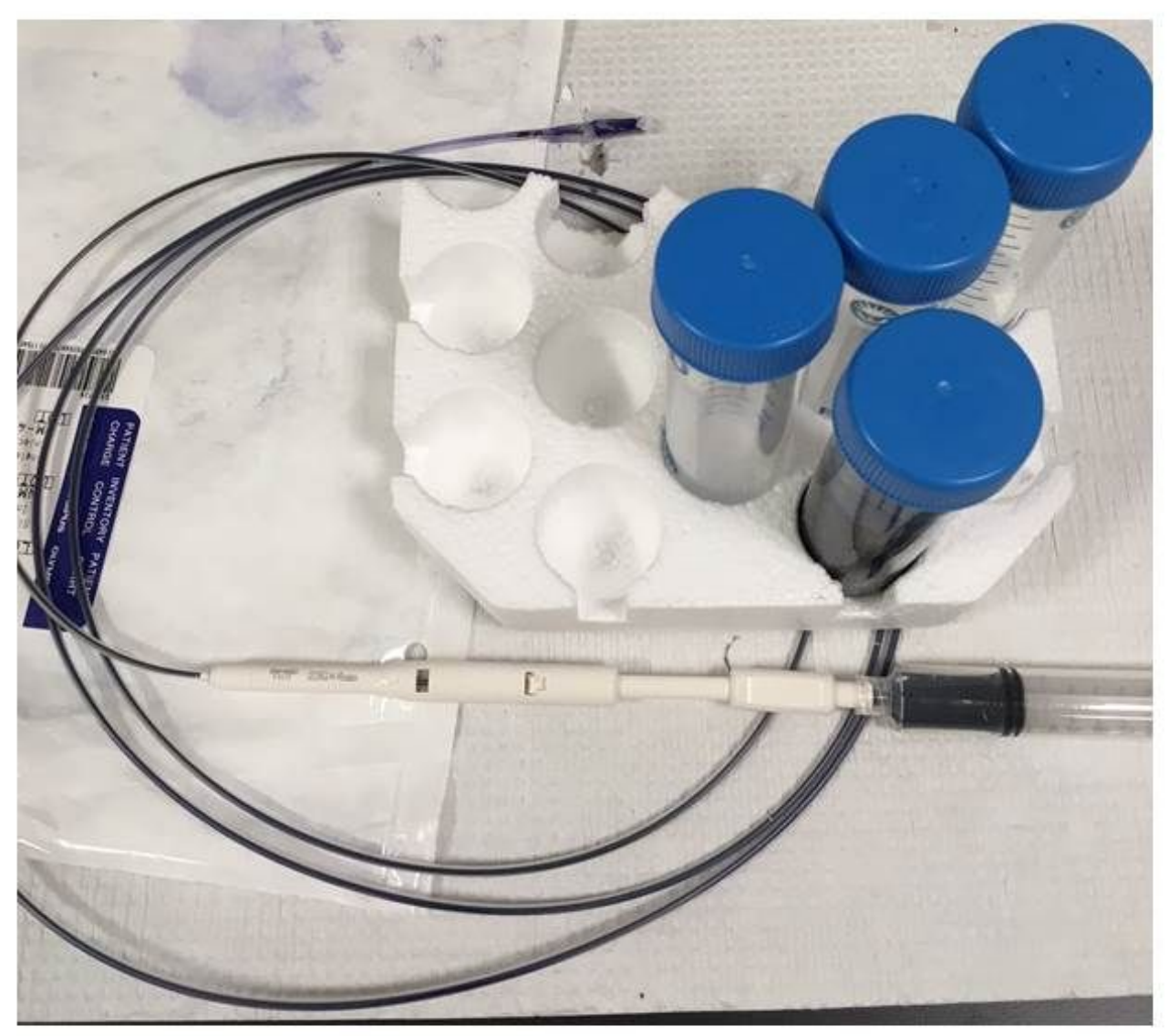

\section{Figure 5}

\section{Figure 5}

The "pen": The tip of the Sclerotherapy catheter is retracted, a small piece of cotton inserted into the tip. The Methylene Blue serves as the "ink", is periodically injected into the catheter via syringe. 


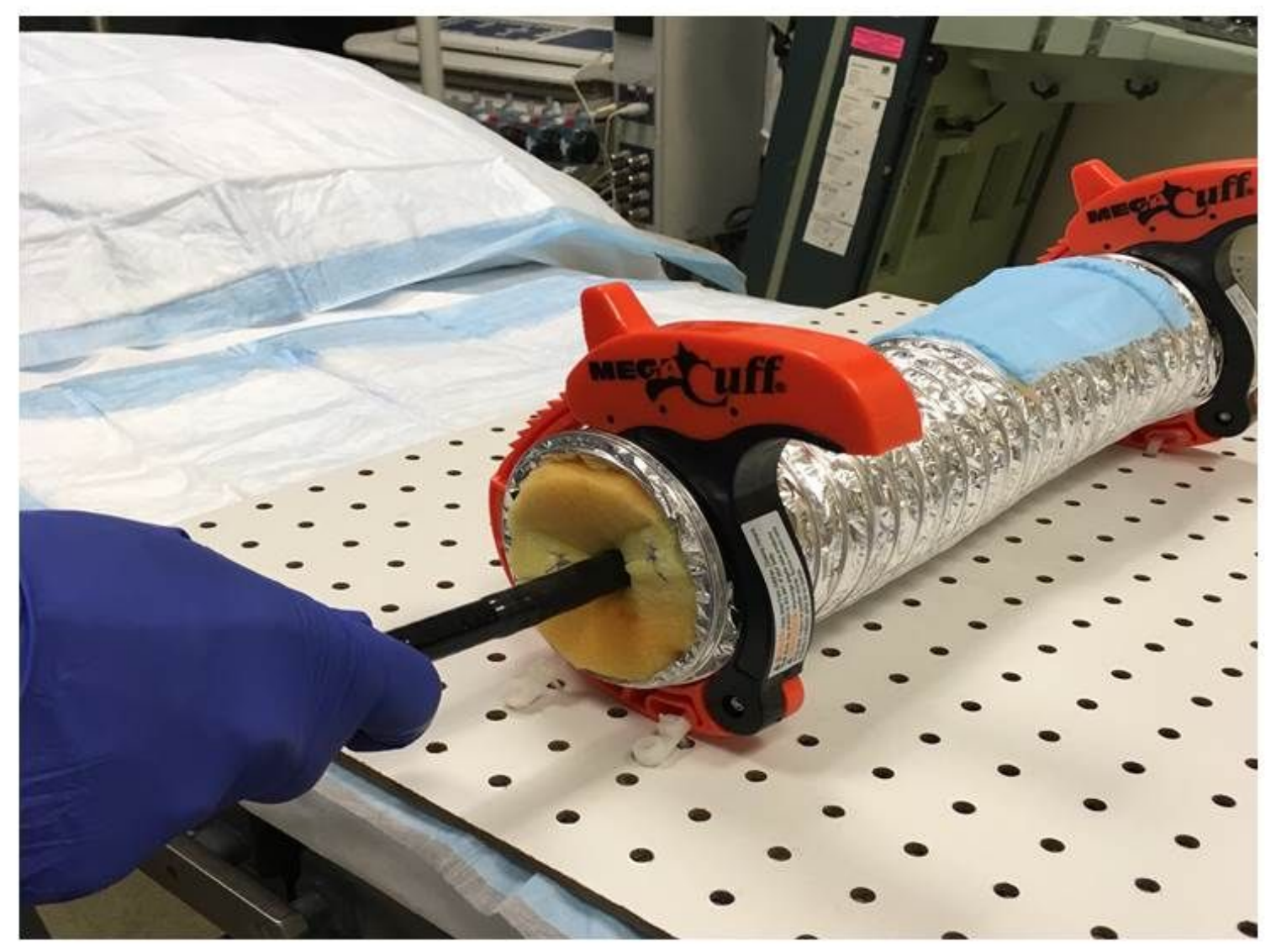

Figure 6

Figure 6

Insertion and orientation of the colonoscope in the model. 


\section{Tattooing Stomach Tissue}

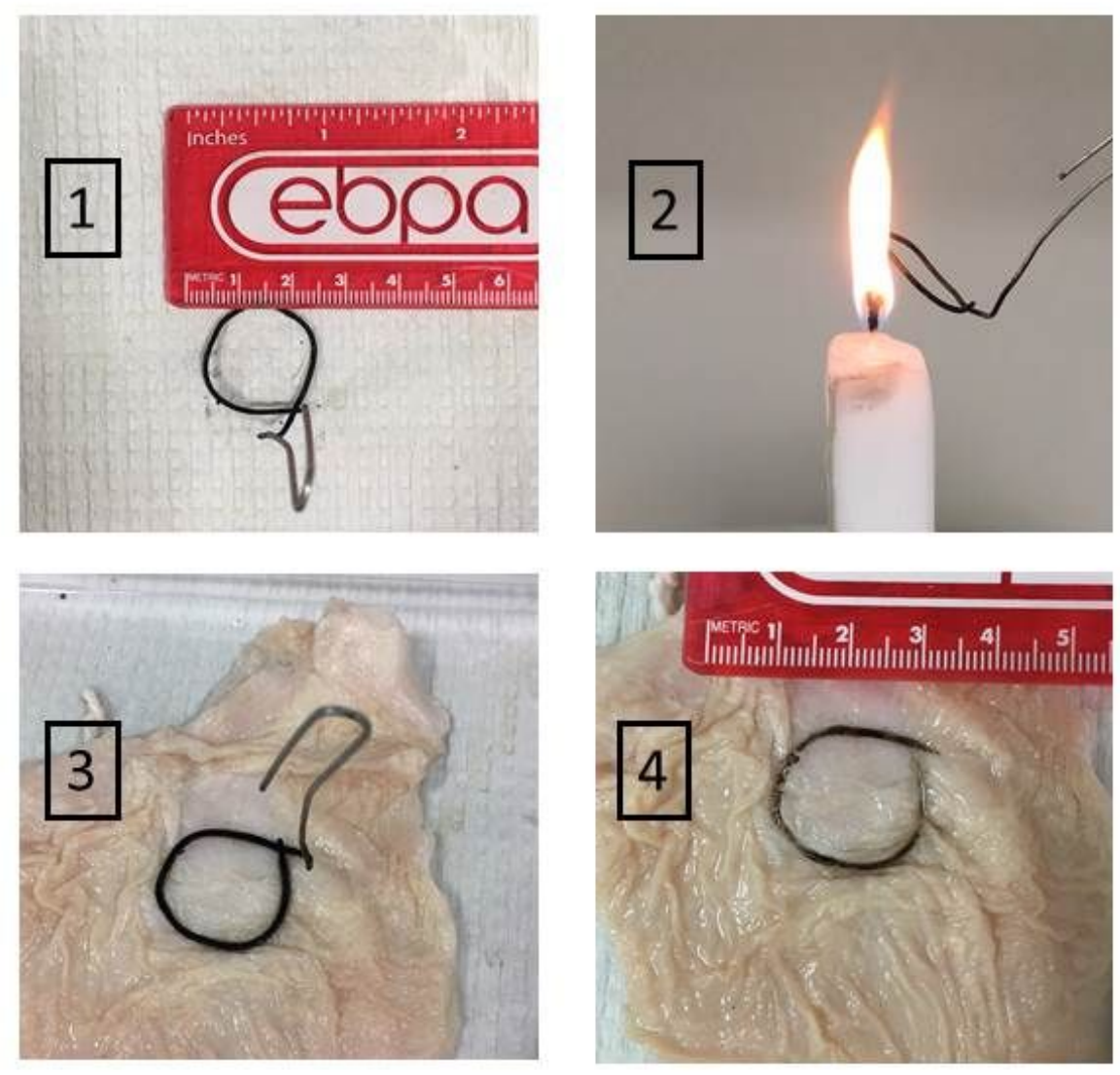

Figure 7

Figure 7

"Branding" a lesion onto our porcine gastric specimen. 


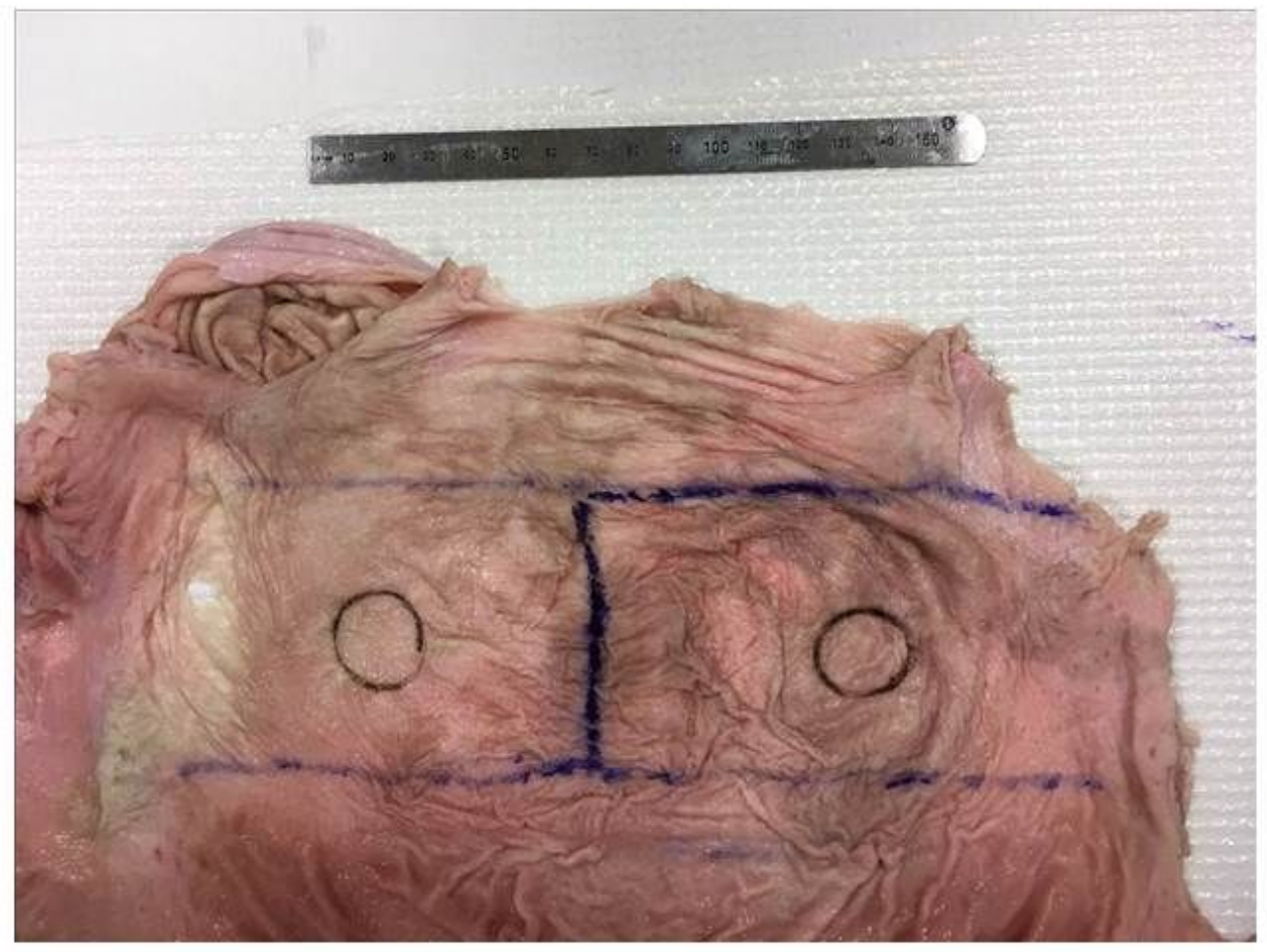

Figure 8

\section{Figure 8}

Full thickness rectangular specimens cut out for each session. 

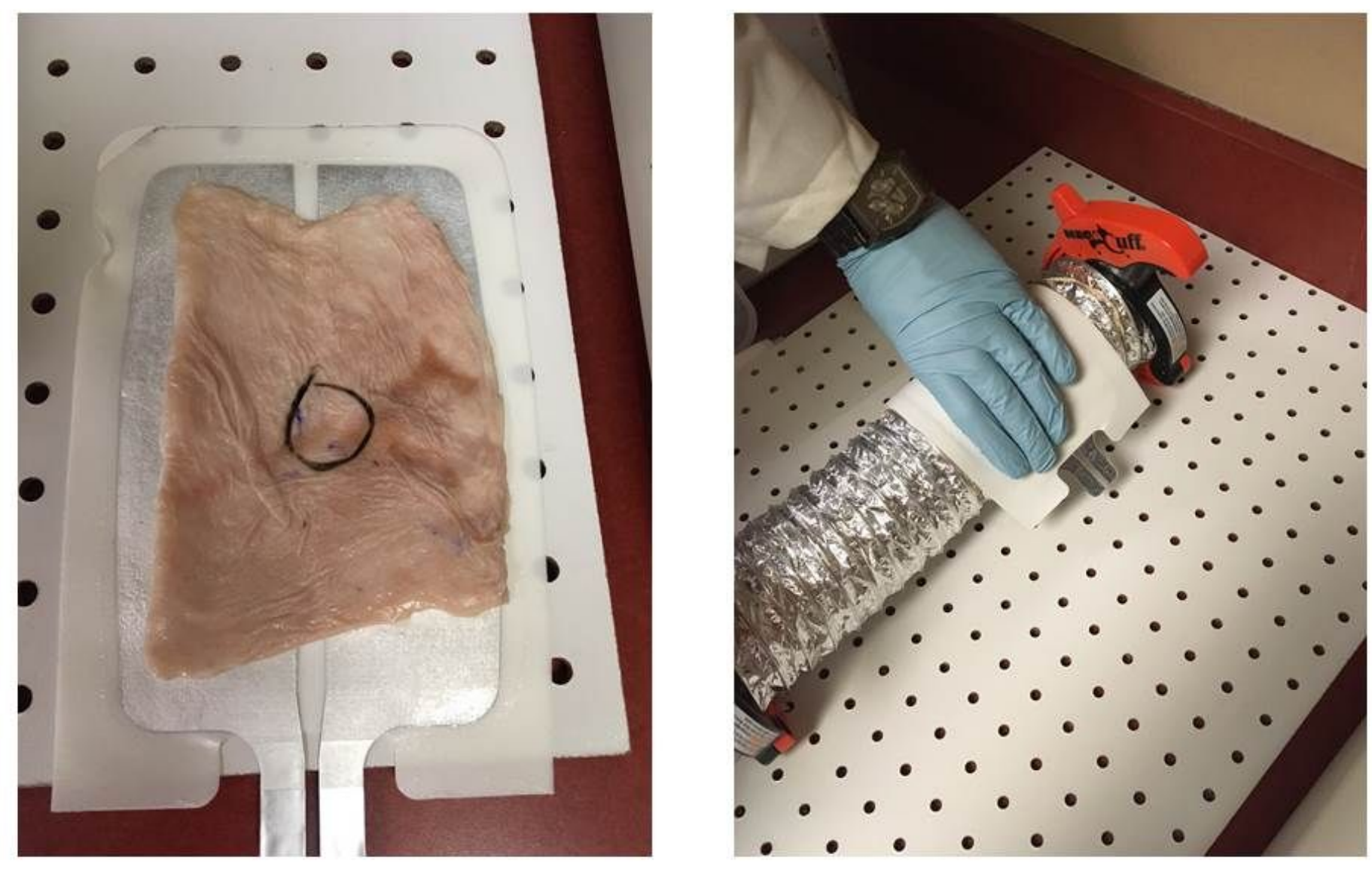

Figure 9

Figure 9

Placement of Stomach on electrocautery pad and integration into "colon" model. 

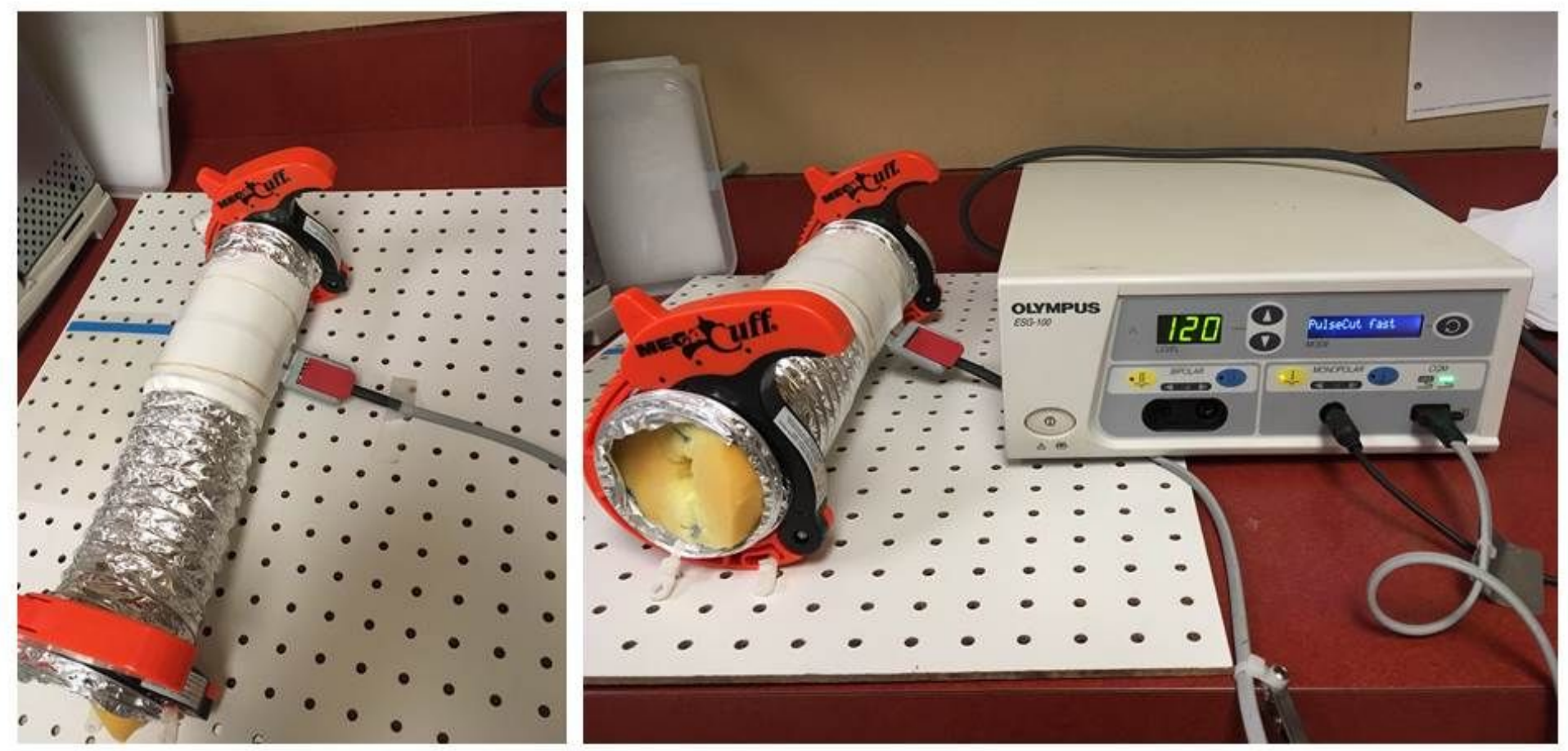

Figure 10

Figure 10

Electrocautery machine and Bovie pad setup. 


\section{Post resection stomach wall and detached lesion}

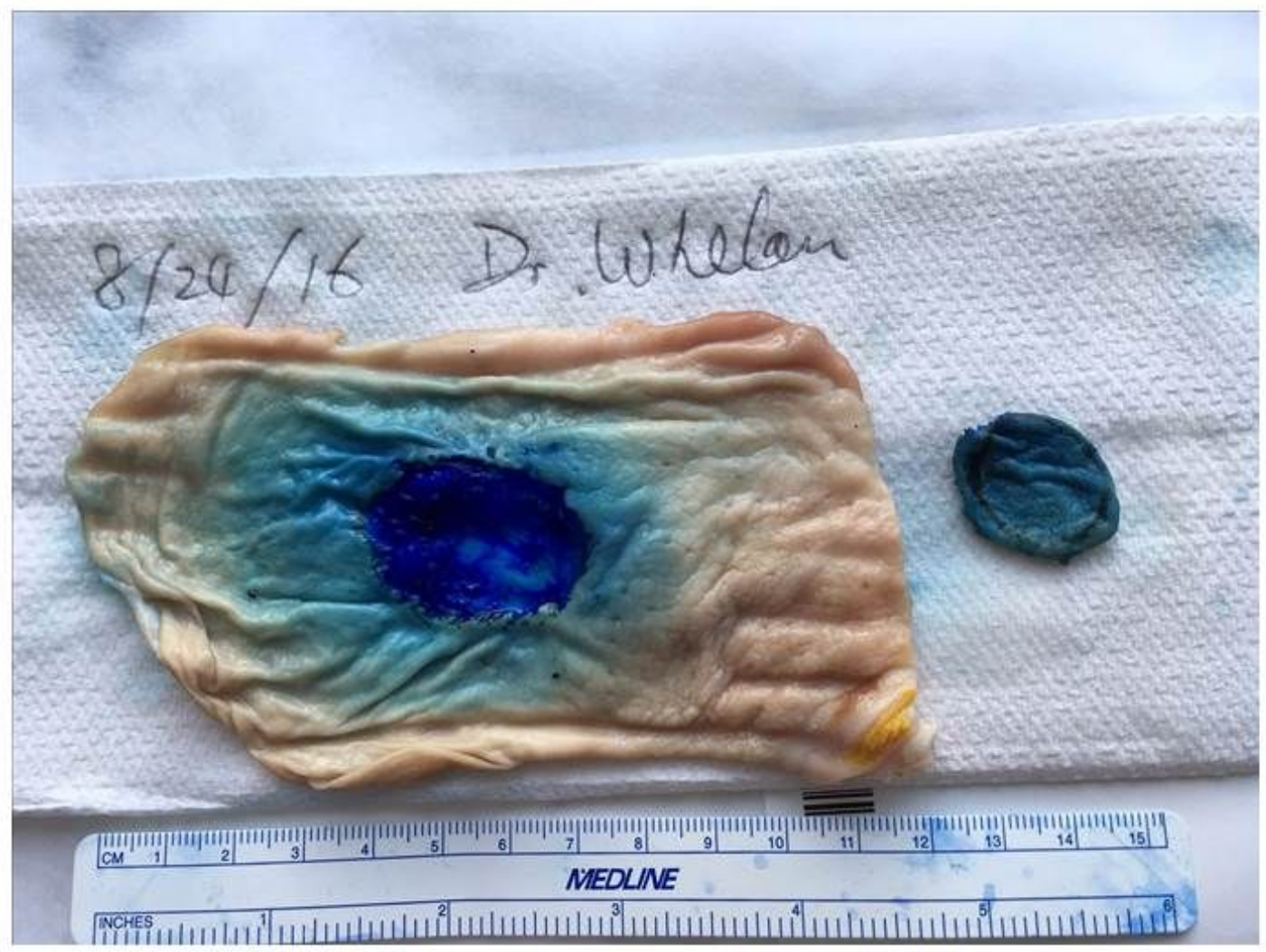

Figure 11

Figure 11

Post ESD, "polyp" removed, resected specimen and mucosal defect inspected. 


\section{Early and later tracings}

Early
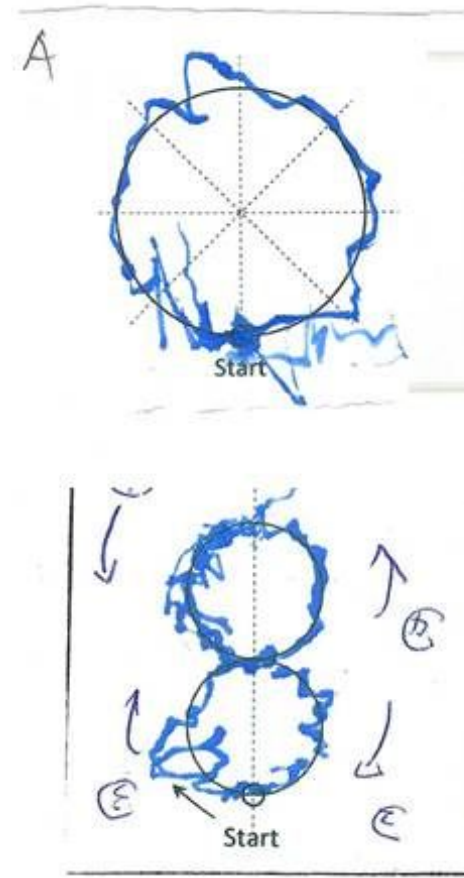

Late
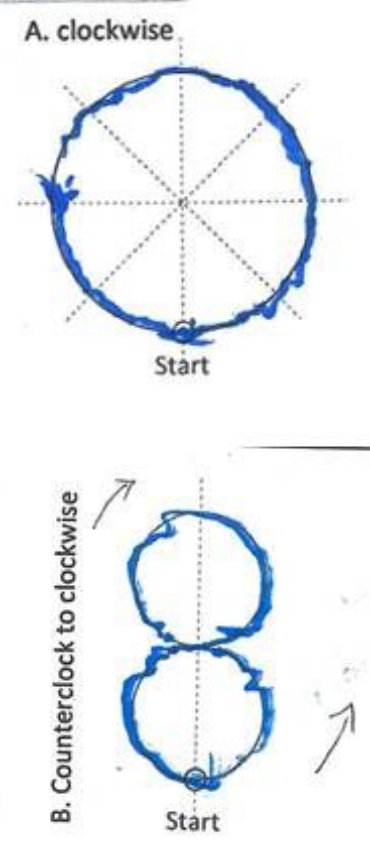

Early
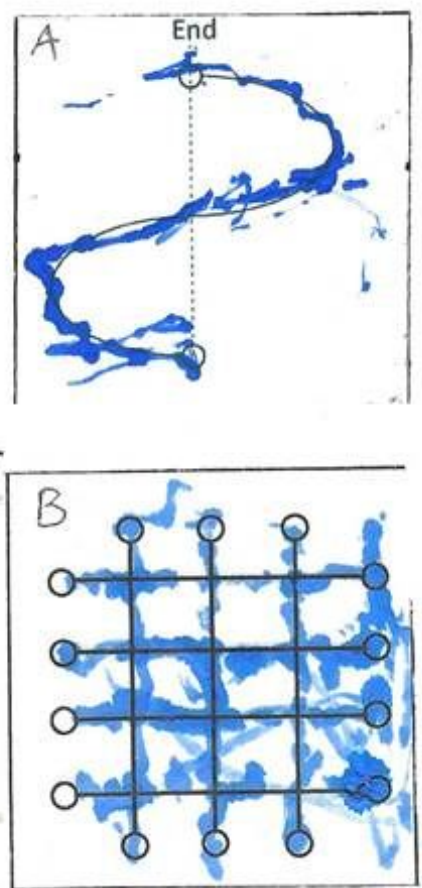

Late
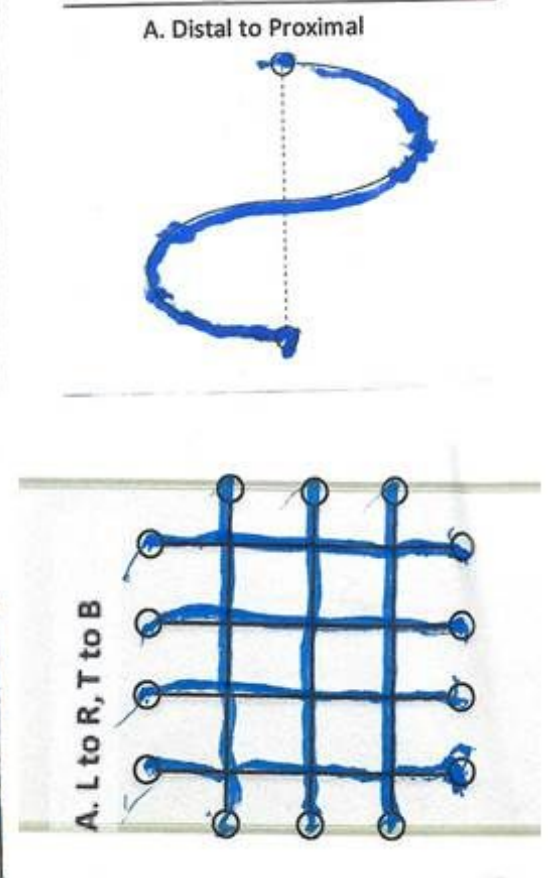

Figure 12

Figure 12

Before training and after training results of Trainee A's Figure Tracing sessions. 


\section{Trainee A's Figure Tracing Times for each pattern}

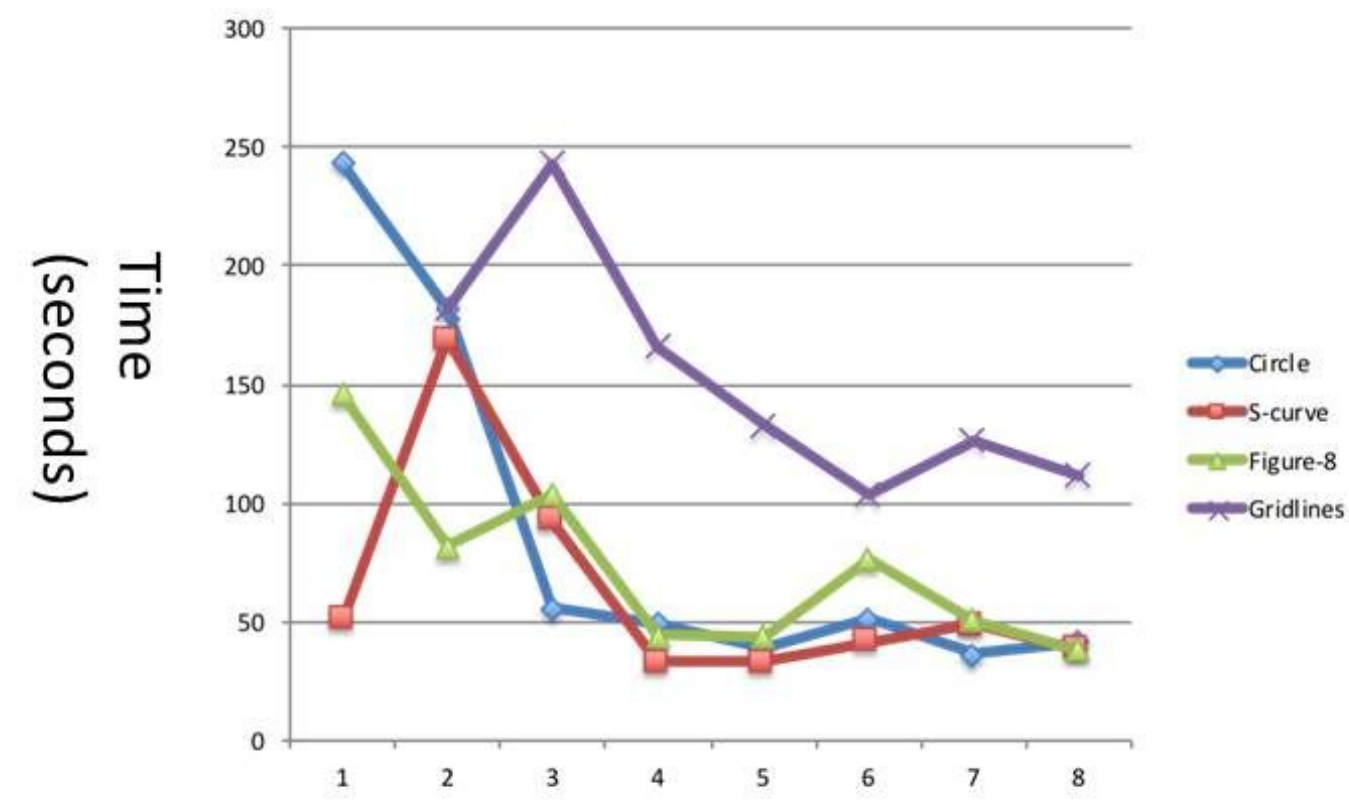

Training session number

Figure 13

Figure 13

Trainee A's results. Time taken to complete each pattern tracing per session for Trainee A. 


\section{Trainee A: Number of pen strokes, gaps \& line deviations for each pattern}
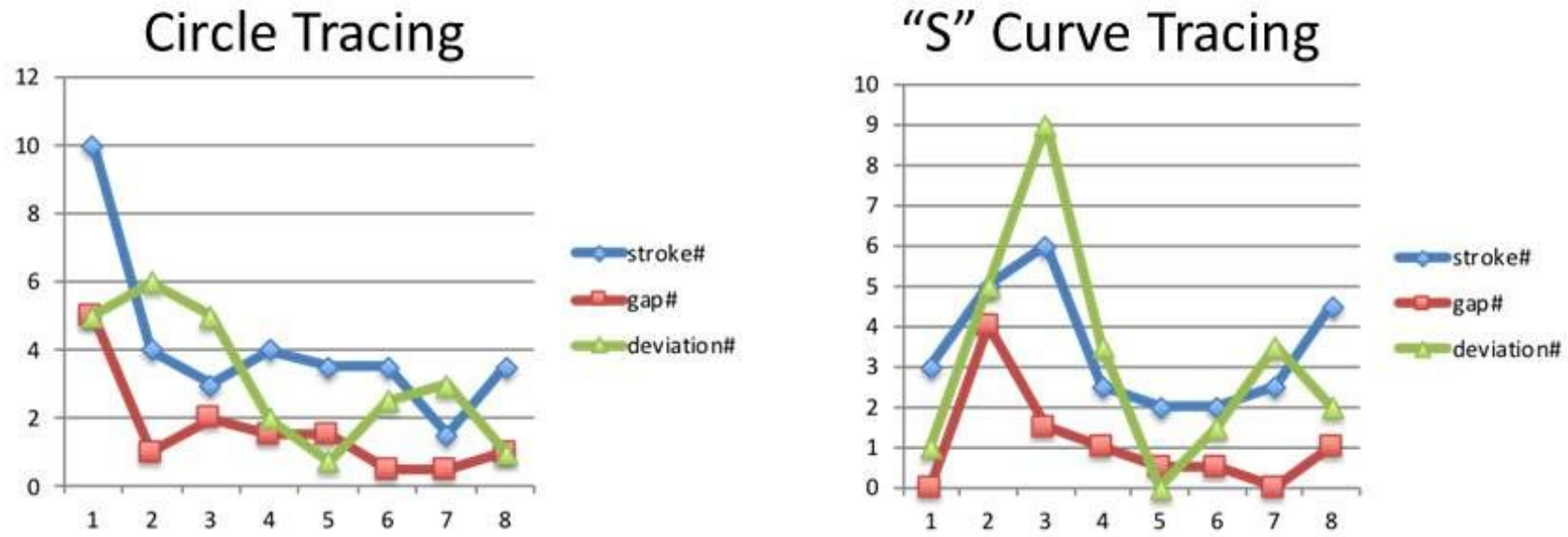

Figure 8 tracing

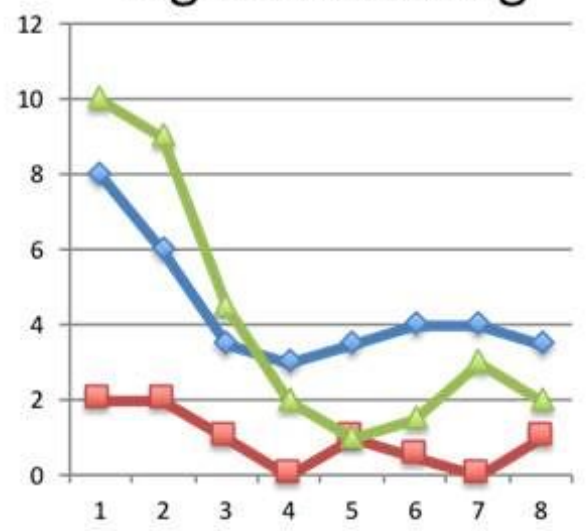

Grid Pattern Tracing

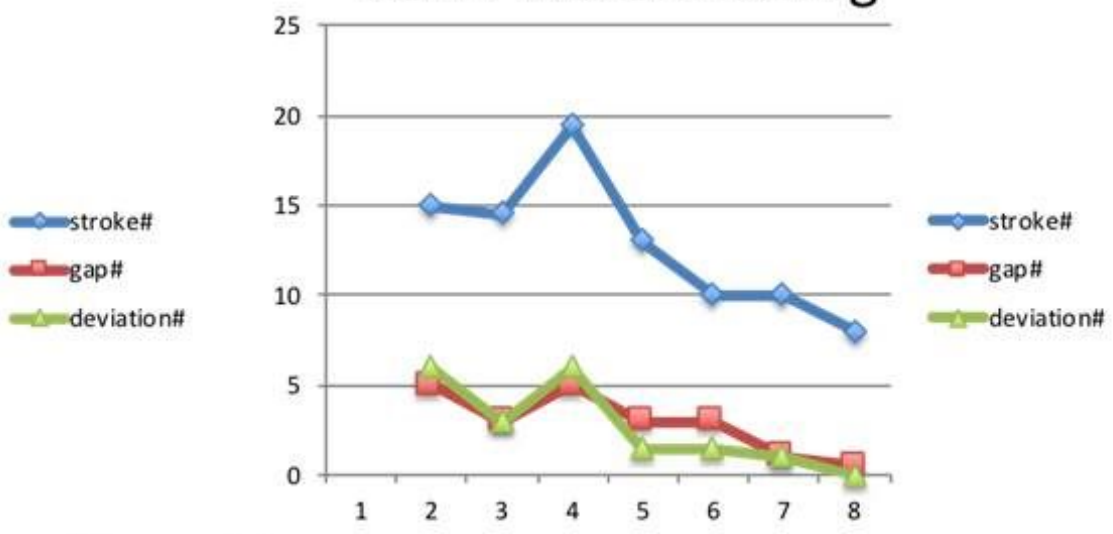

Figure 14

\section{Figure 14}

Trainee A's results. Number of pen strokes, gaps and line deviations for each pattern per session for Trainee A ( $x$ axis: Training session number, y axis: Number of strokes, gaps \& line deviations) 


\section{Trainee B's Figure Tracing Times for Each Pattern}

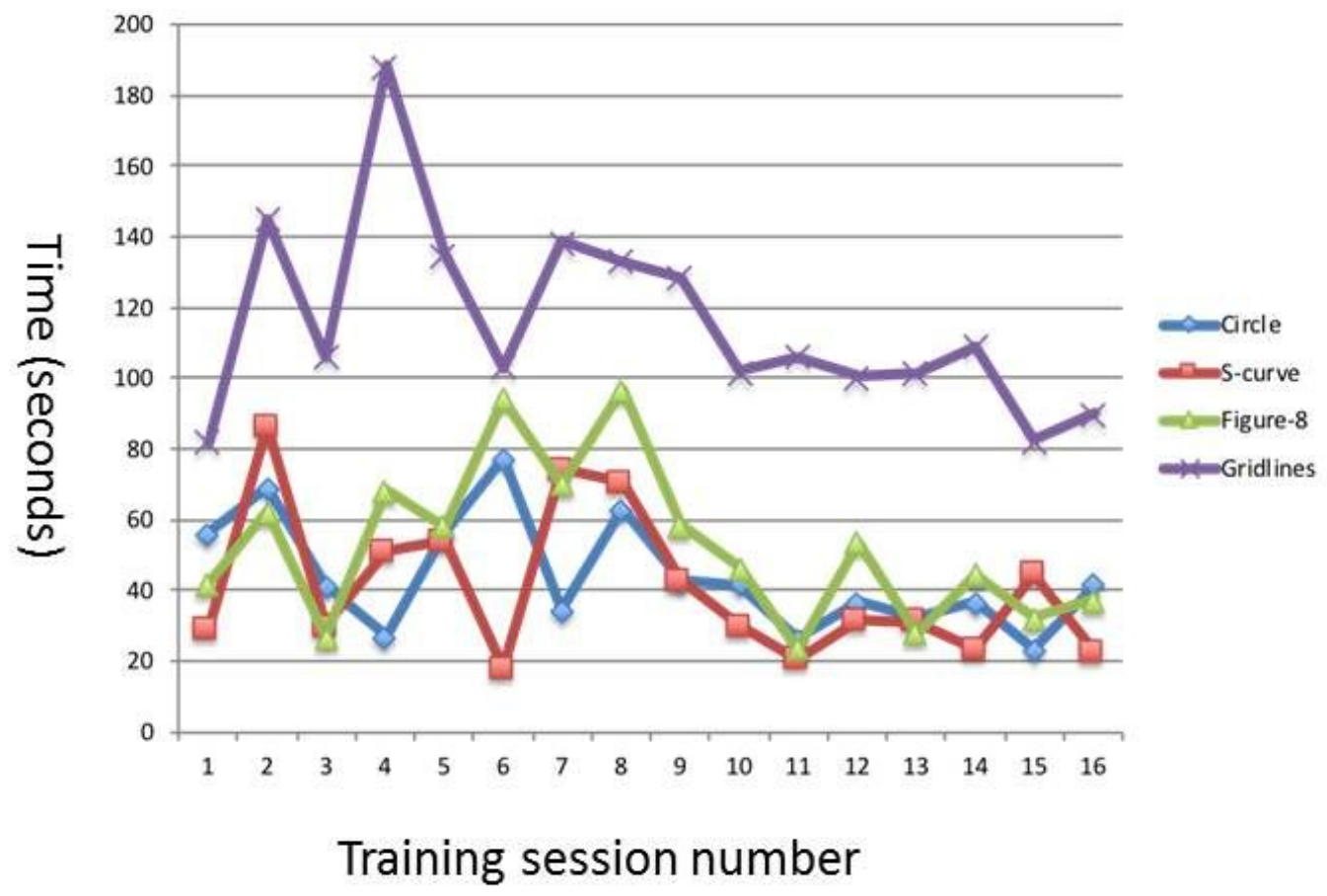

Figure 15

Figure 15

Trainee B's results. Time taken to complete each pattern tracing per session for Trainee B. 


\section{Trainee B: Number of pen strokes, gaps, line deviations for each pattern}

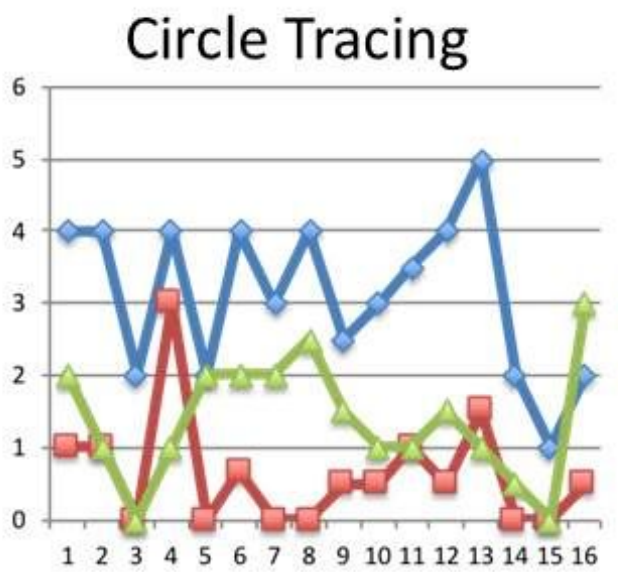

Figure 8 Tracing

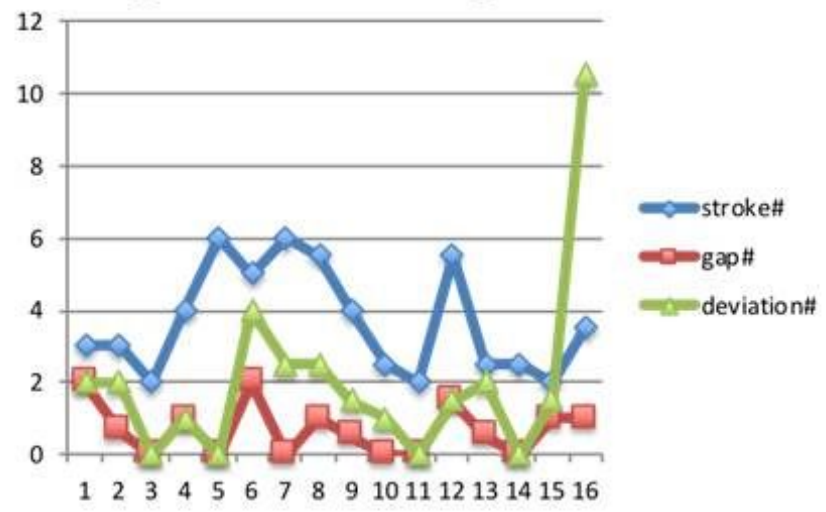

Figure 16

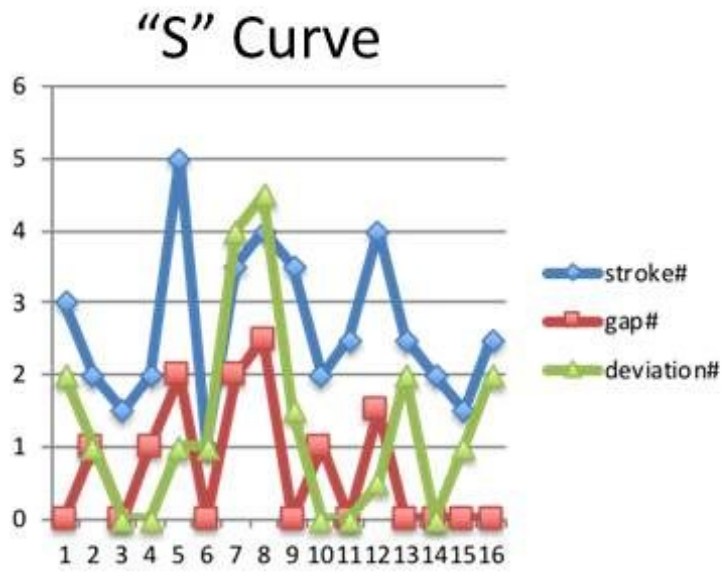

\section{Grid Pattern Tracing}

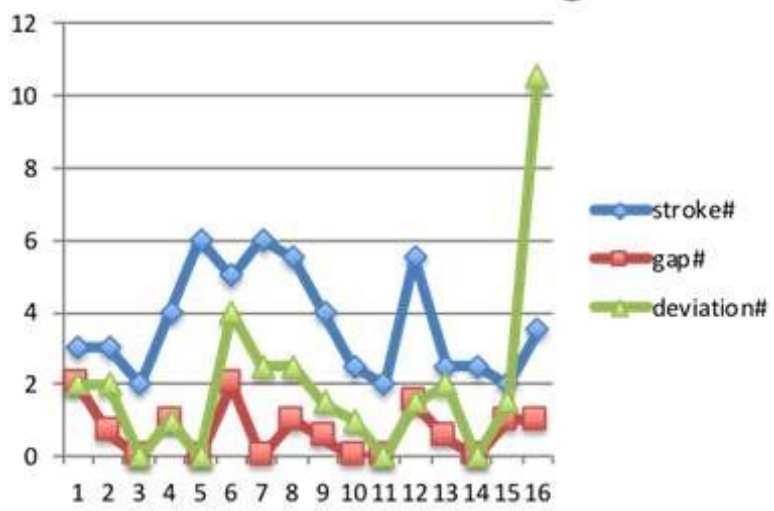

Figure 16

Trainee B's results. Number of pen strokes, gaps and line deviations for each pattern per session for Trainee B ( $x$ axis: Training session number, y axis: Number of strokes, gaps \& line deviations) 


\section{Trainee A and B's first session completion times}

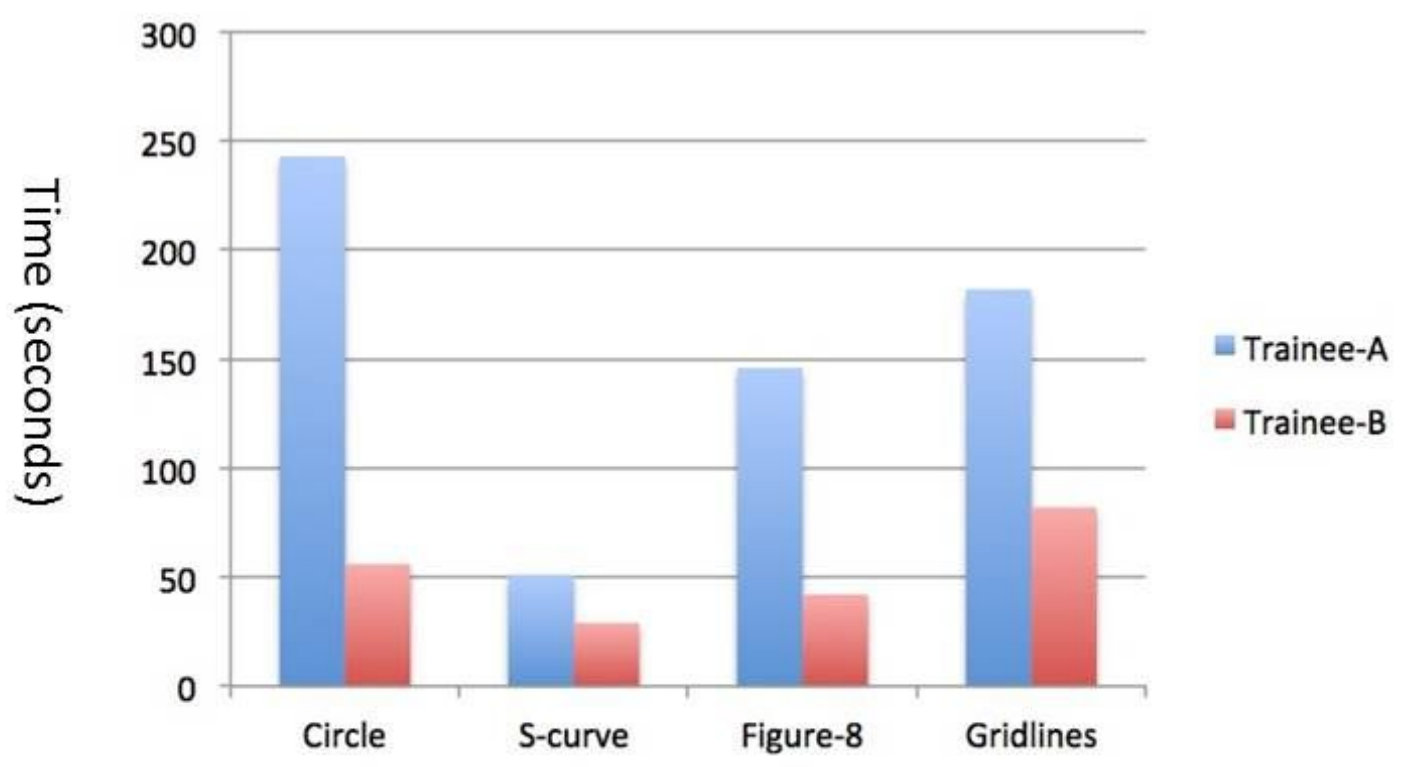

Different figures

Figure 17

Figure 17

Trainee B's results. Comparison of first session completion times for each pattern tracing for trainee A and $\mathrm{B}$. 


\section{Pig stomach ESD: Number of superficial muscle injuries per case}

\section{Trainee-A}

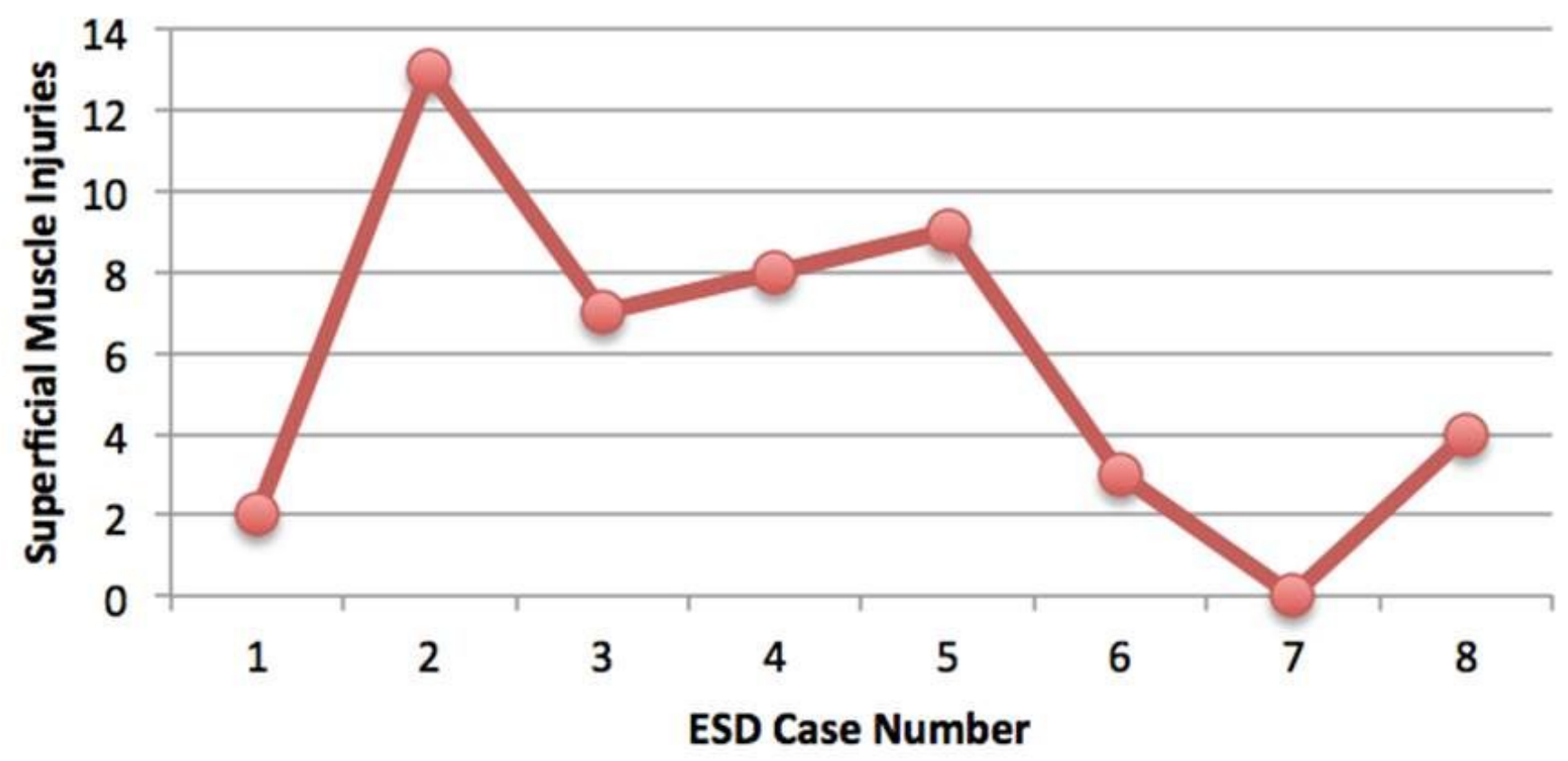

Figure 18

Figure 18

Trainee A's results. Number of superficial muscularis propria injuries per pig stomach ESD case for Trainee A. 


\section{Pig stomach ESD : Number of full thickness injuries per case}

\section{Trainee-A}

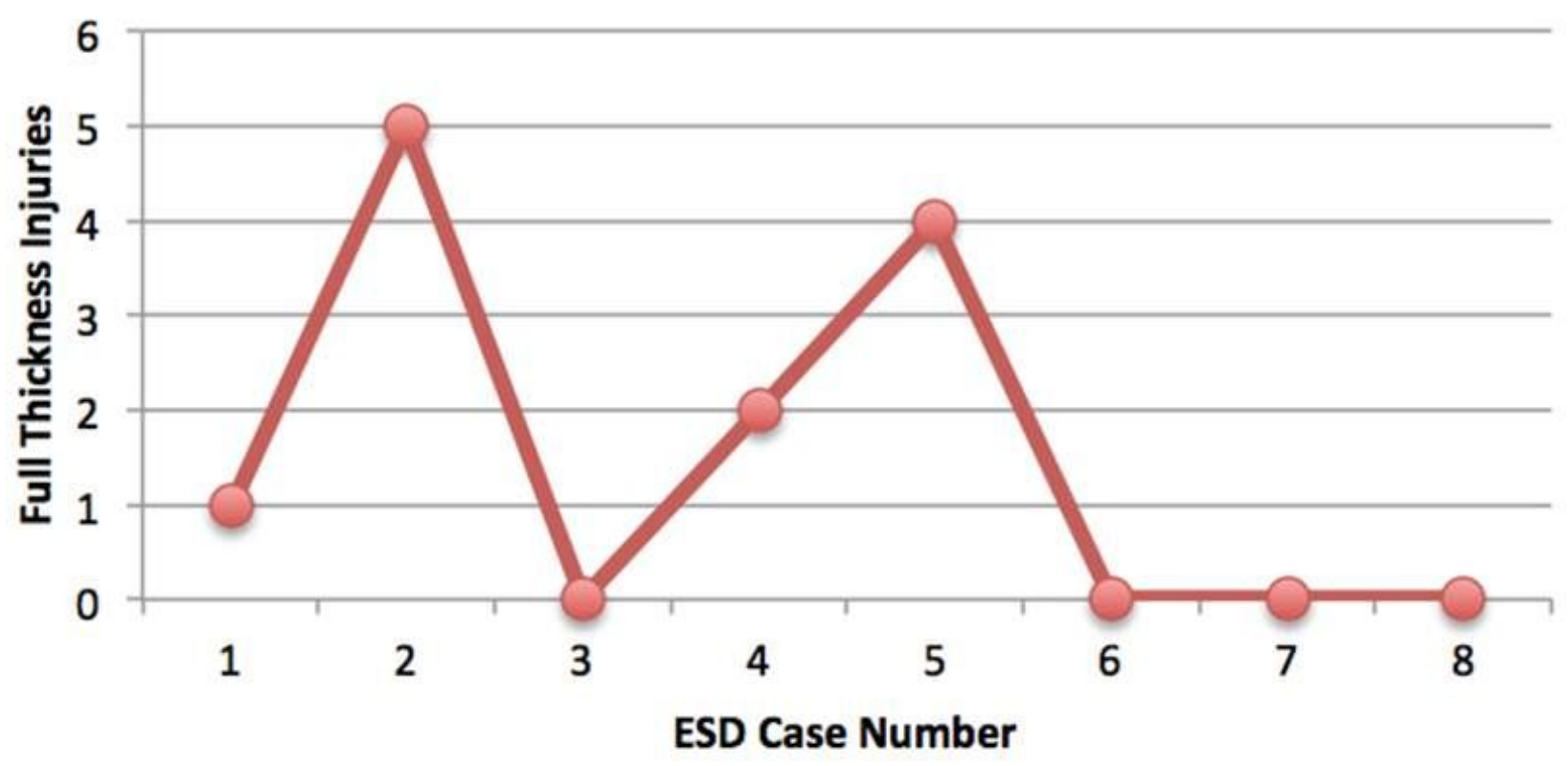

Figure 19

Figure 19

Trainee A's results. Number of full thickness perforations per pig stomach ESD case for Trainee A. 


\section{Pig stomach ESD: Number of superficial muscle injuries per case}

\section{Trainee-B}

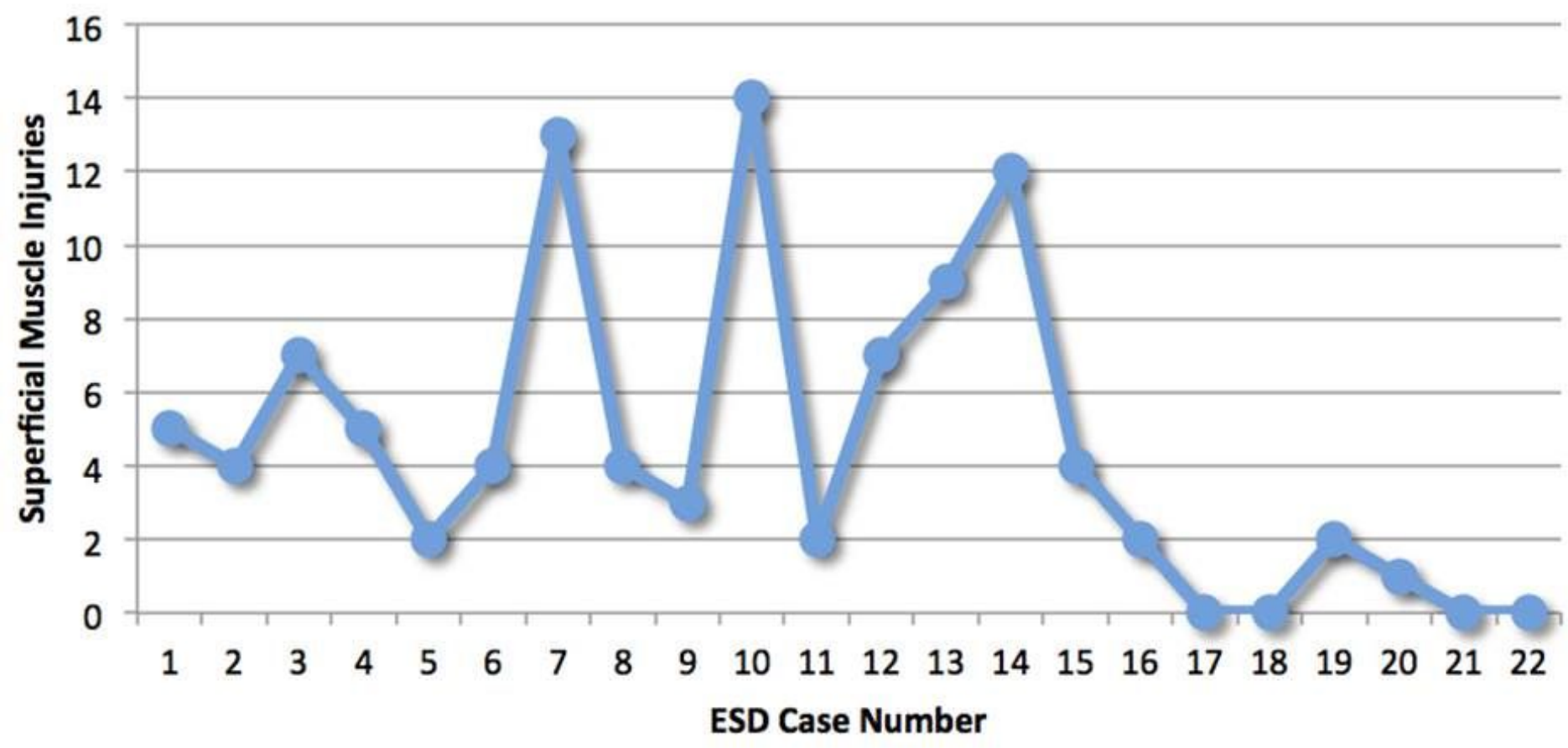

Figure 20

Figure 20

Trainee B's results. Number of superficial muscularis propria injuries per pig stomach ESD case for Trainee B. 


\section{Pig stomach ESD: Number of full thickness perforations per case}

Trainee-B

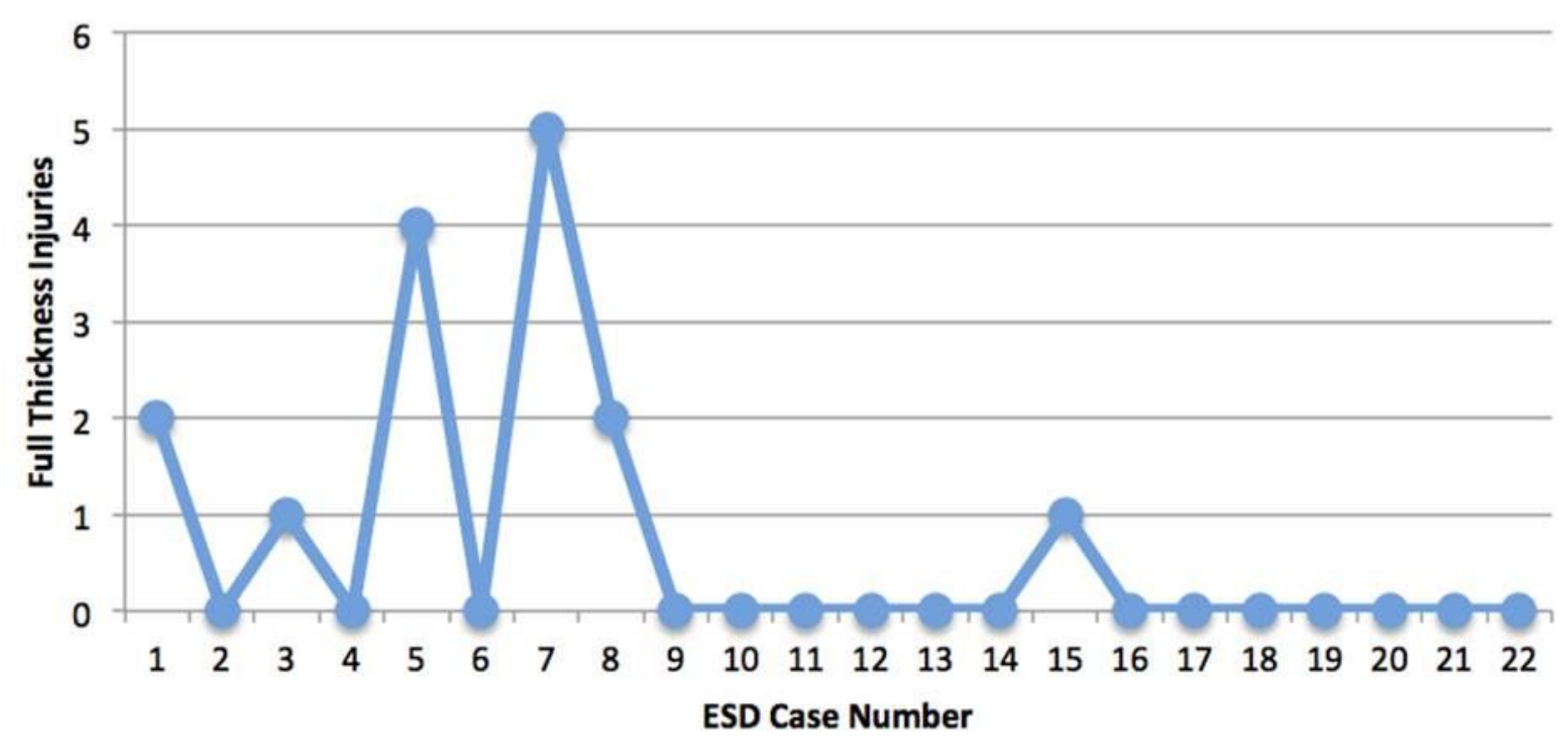

Figure 21

Figure 21

Trainee B's results. Number of full thickness perforations per pig stomach ESD case for Trainee B. 


\section{ESD case times}

\section{Trainee-A}

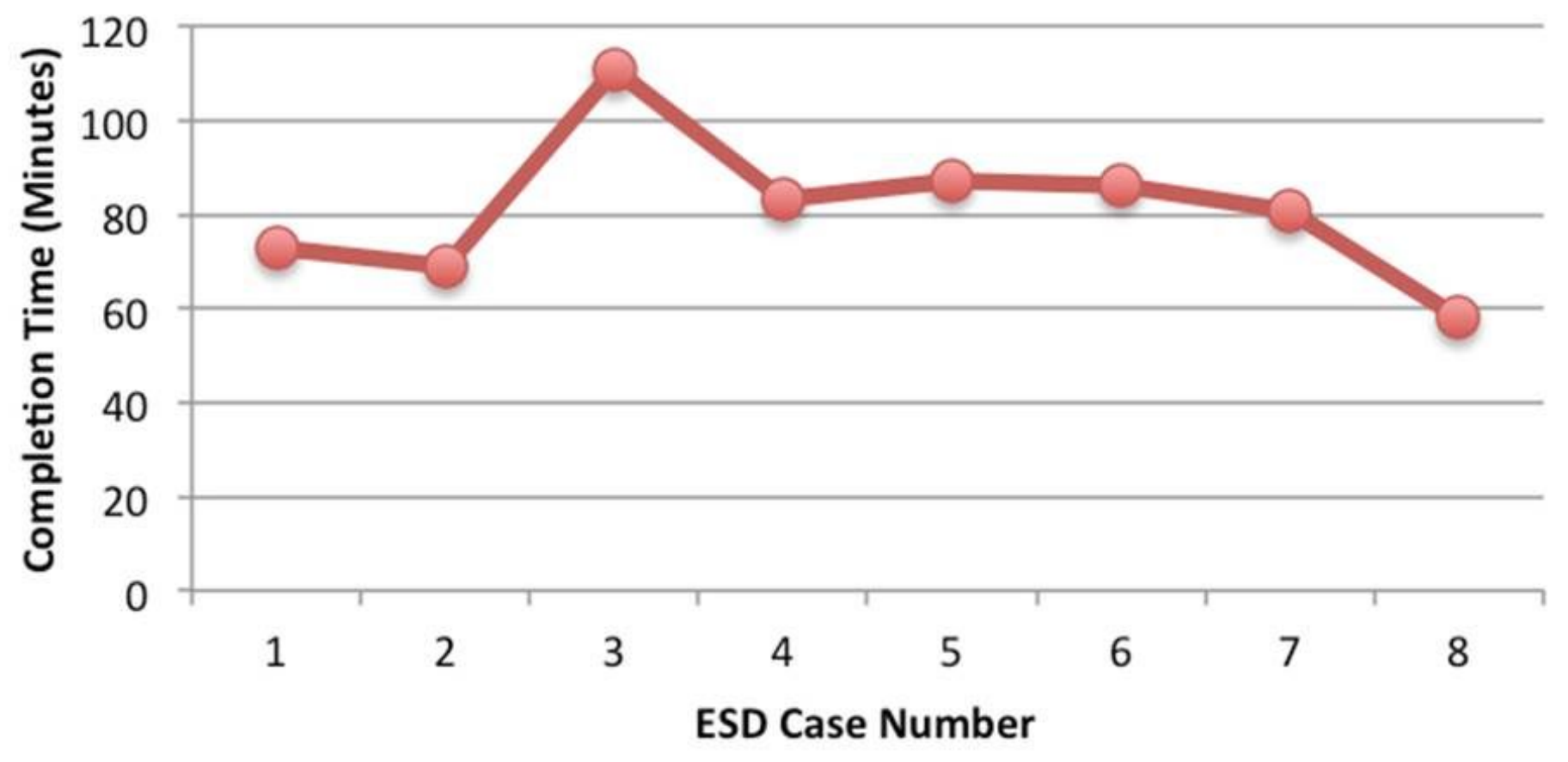

Figure 22

Figure 22

Trainee A's results. Time to complete each ESD session for Trainee A. 


\section{ESD case times}

Trainee-B

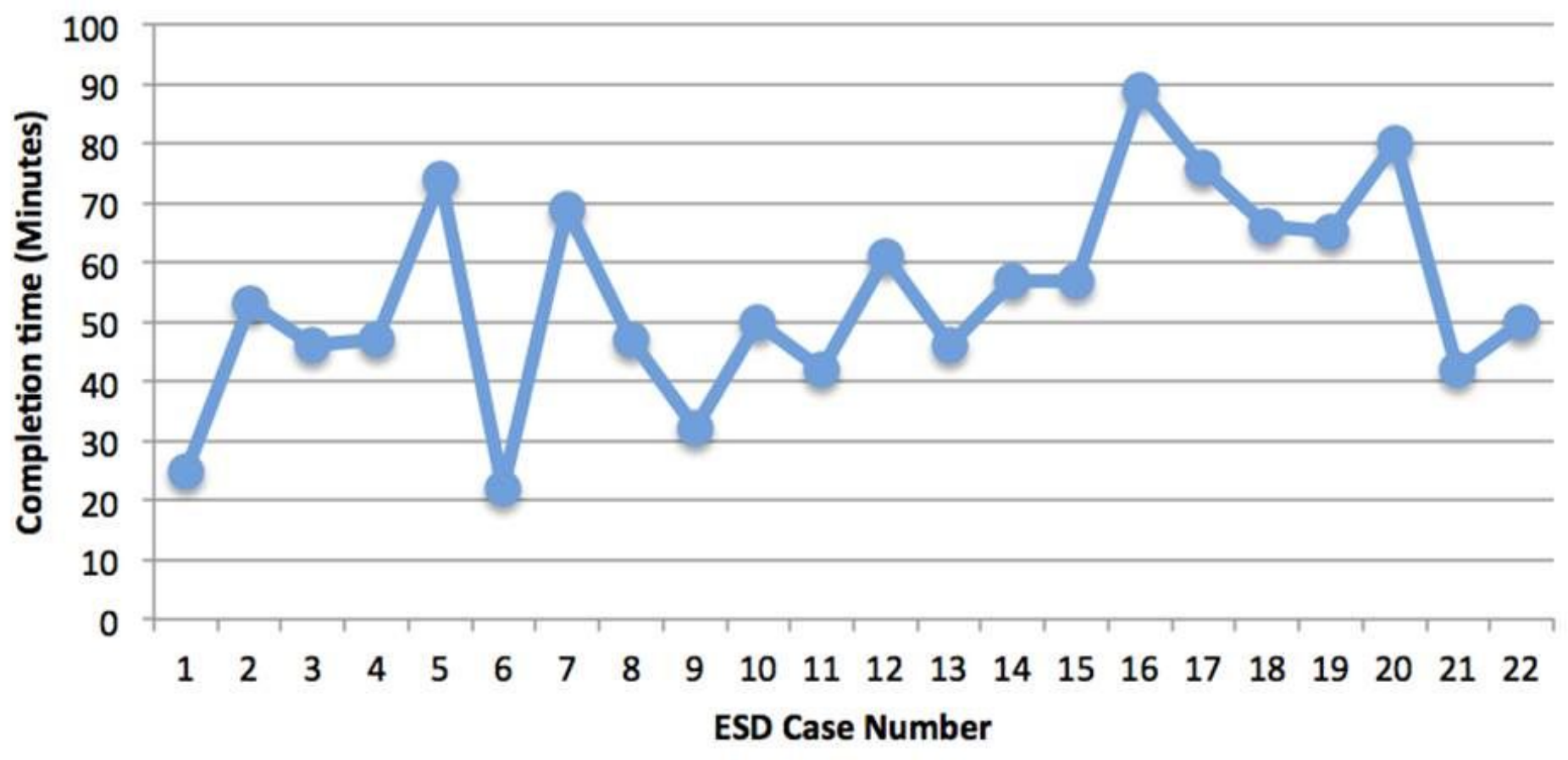

Figure 23

Figure 23

Trainee B's results. Time to complete each ESD session for Trainee B.

\section{Supplementary Files}

This is a list of supplementary files associated with this preprint. Click to download.

- pigstomachvideo11.mov

- pigstomachvideo1.mov

- pigstomachvideo2.mov

- pigstomachvideo3.mov

- pigstomachvideo5.mov

- pigstomachvideo8.mov

- pigstomachvideo12.mov 
- pigstomachvideo4.mov

- pigstomachvideo10.mov

- pigstomachvideo9.mov

- pigstomachvideo6.mov

- pigstomachvideo7.mov 